$$
\text { الو اقع الافتر اضي كوسيط إبداعي في فنون الرسم الرقمي }
$$

Virtual Reality as a Creative Medium in Digital Drawing

$$
\text { (مدرس بقسم الجر افيك ـ كلية الفنون الجميلة ـ جامعة }
$$

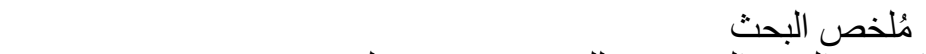

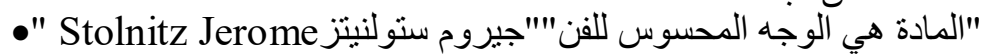

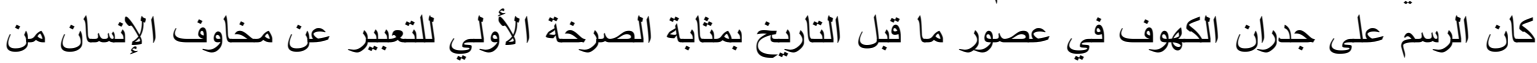

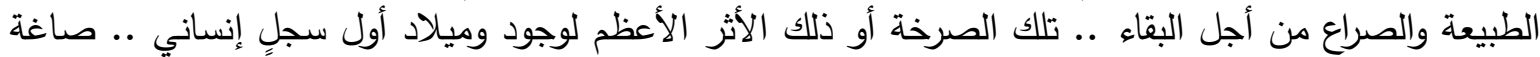

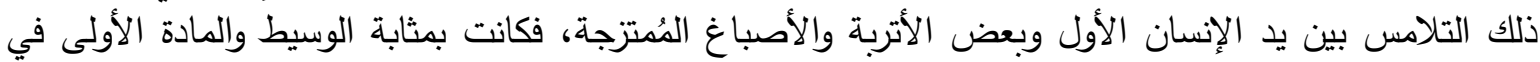

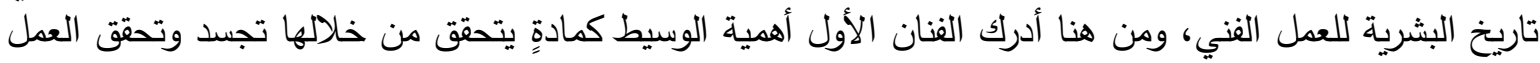

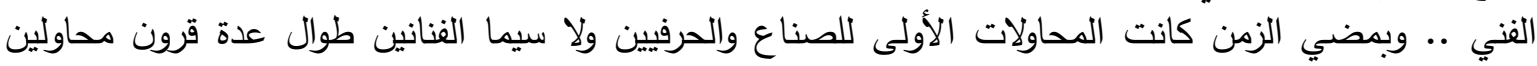

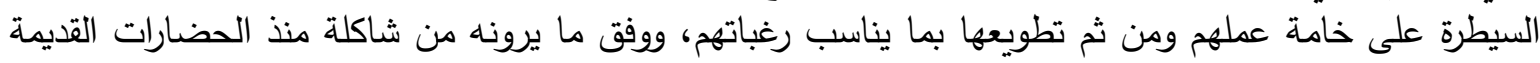

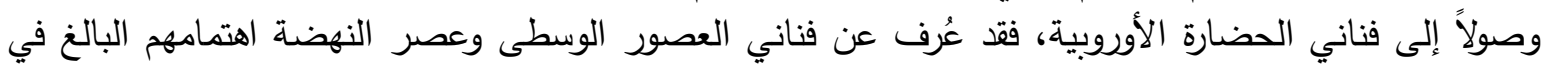

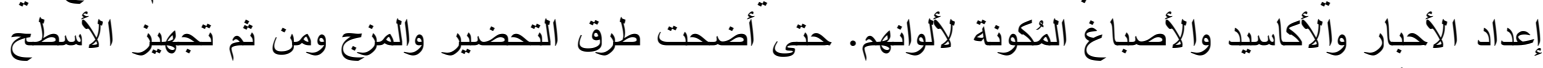

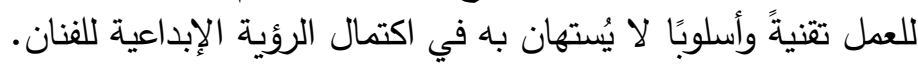

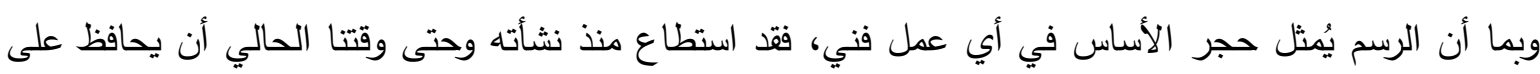

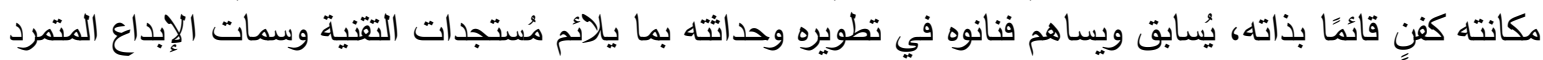

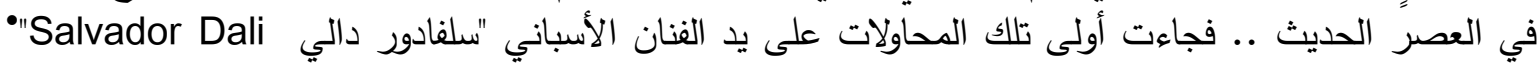

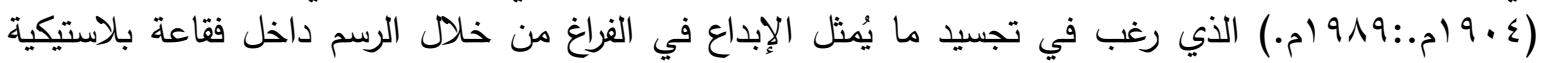

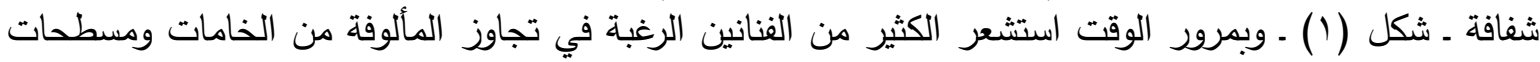

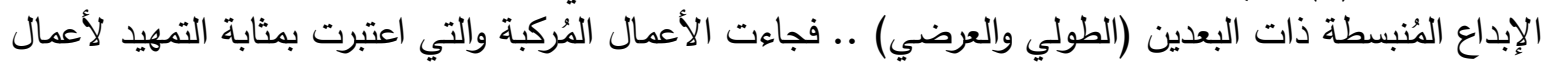

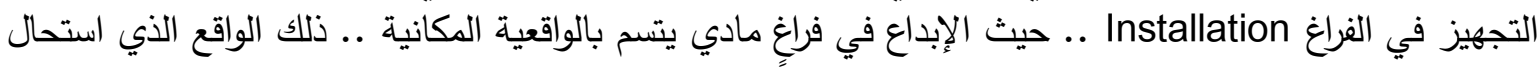

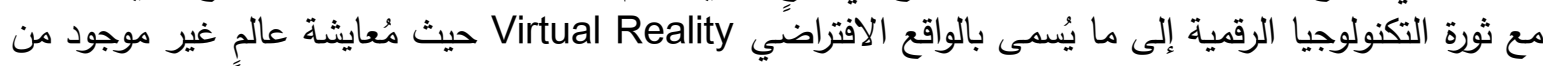

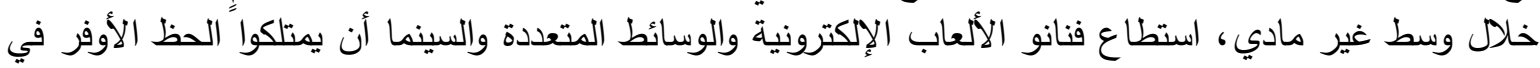

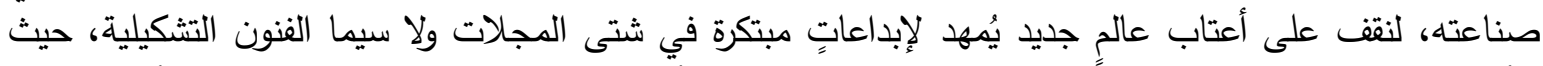

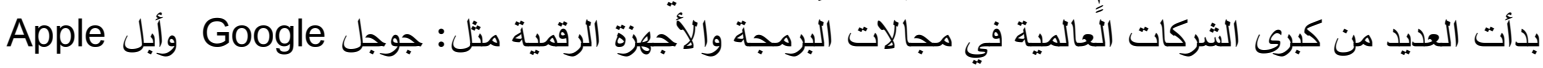

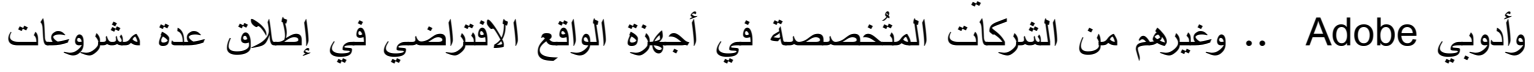

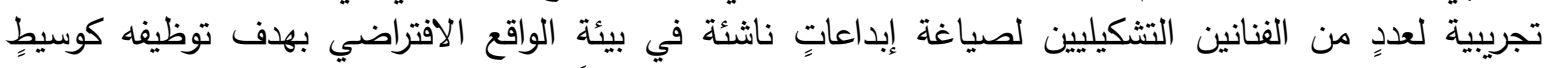

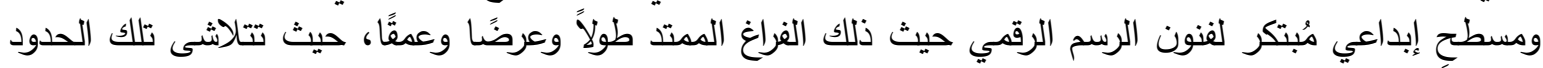

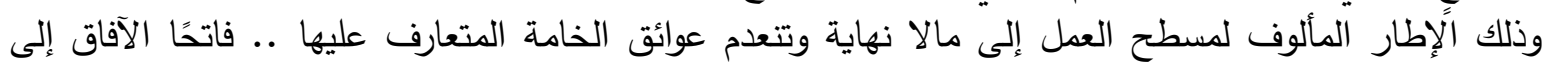

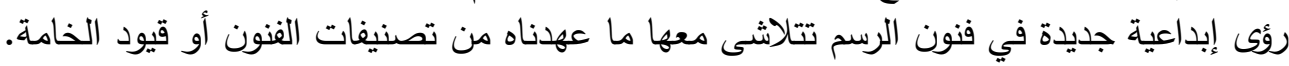

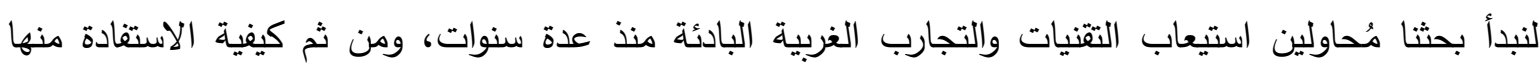

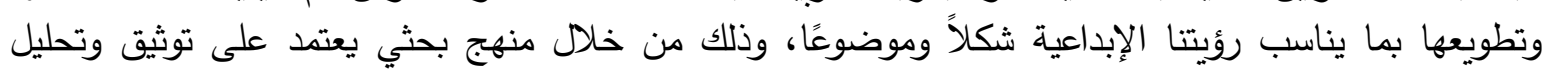

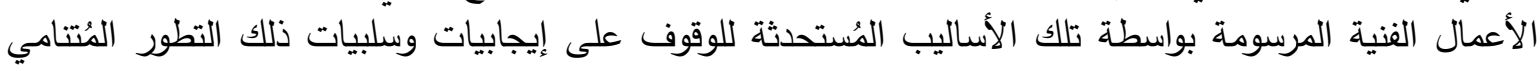
للإبداعات الرقمية في فنون الرسم. الإل

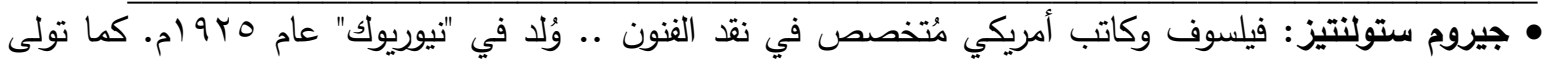

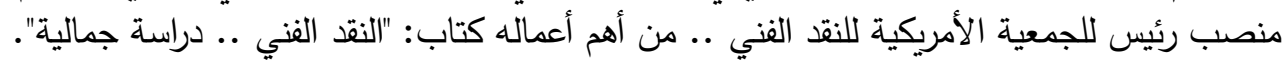

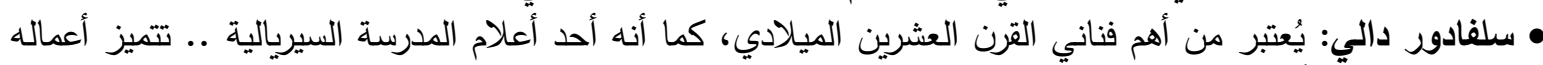

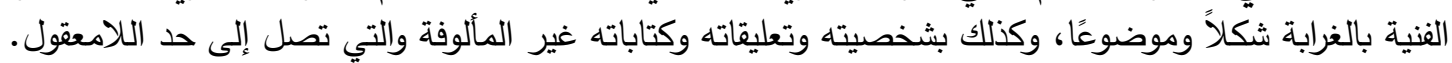


الكلمات المُفتاحية واقع - وسيط ـ افتراضي - رسم - رقمي

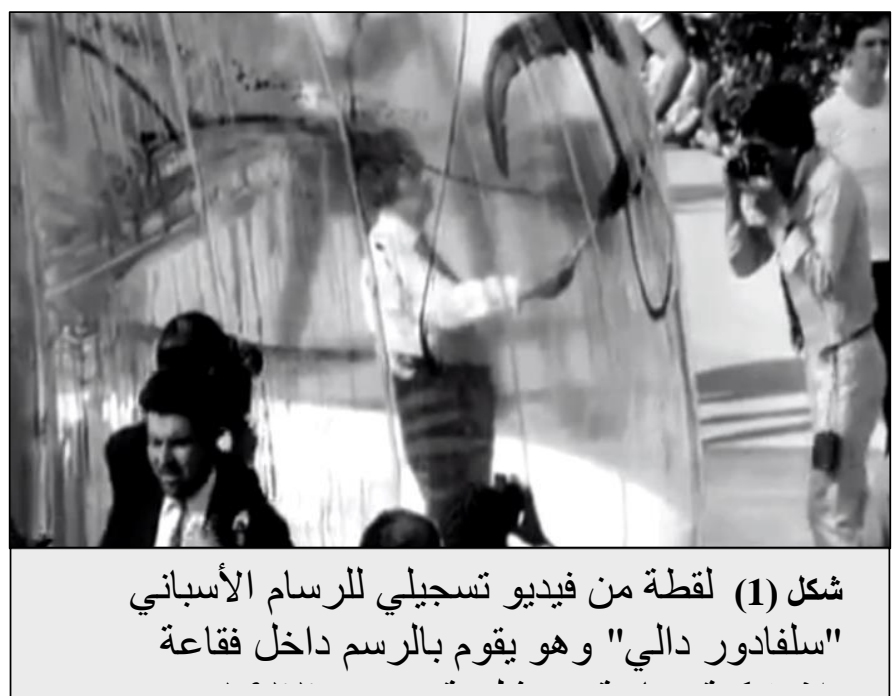

تُعتبر ممارسة الفنون من أحد أهم الممارسات

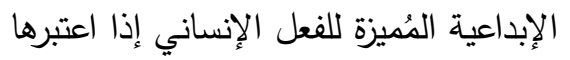
بعض المفكرين بمثابة أحدى علامات الإنسان إذات الإن

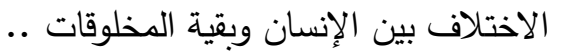

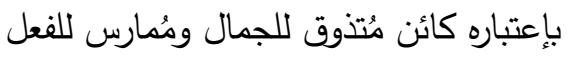

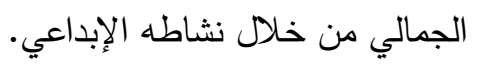

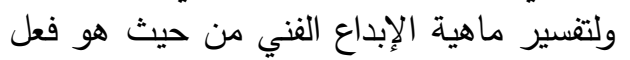

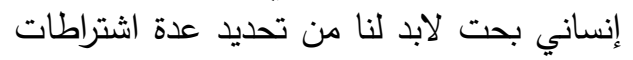

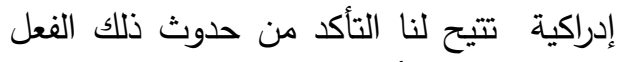
الإبداعي وبقاء أثره في واقعنا .. ذلك التاك الواقع الذي استحال منذ قديم الأزل وحتي عالئ عالمنا

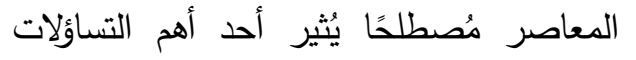

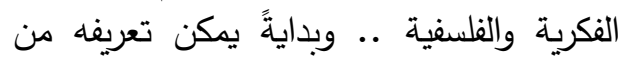

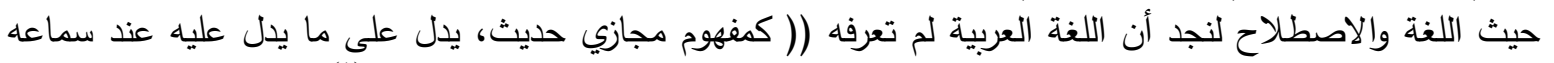

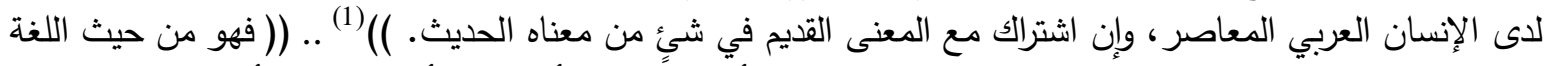

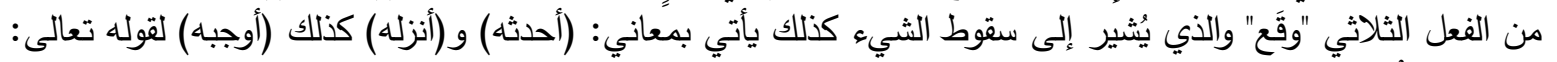

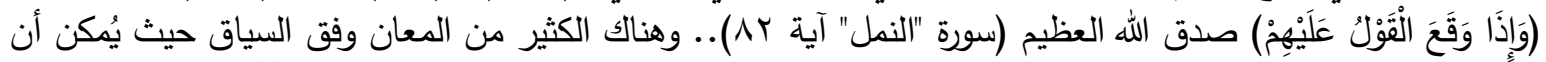

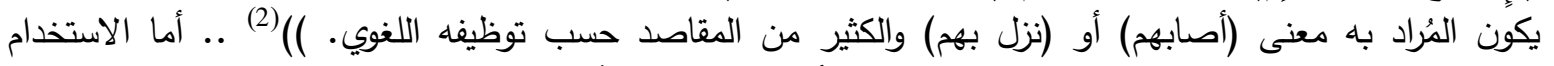

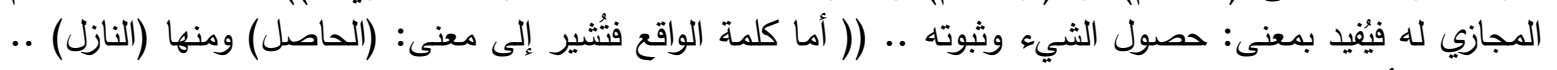

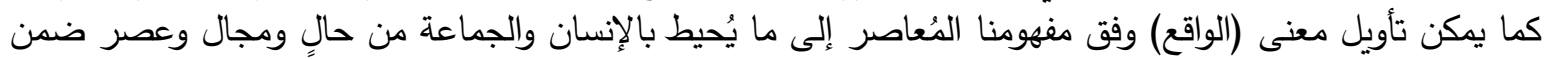

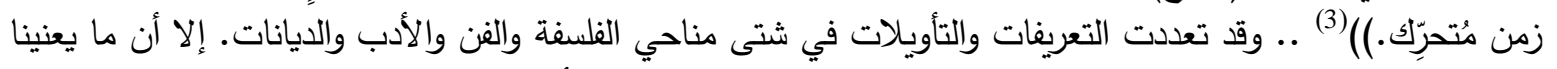

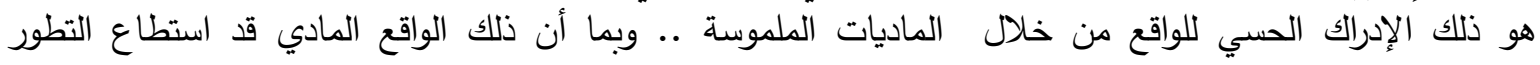

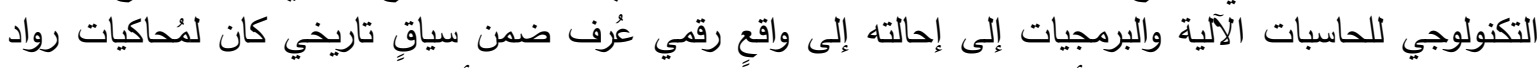

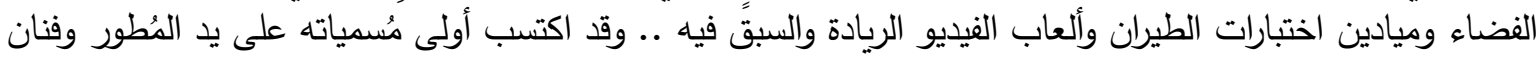

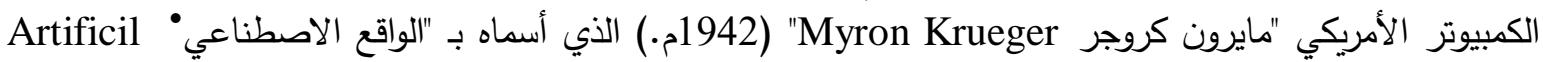

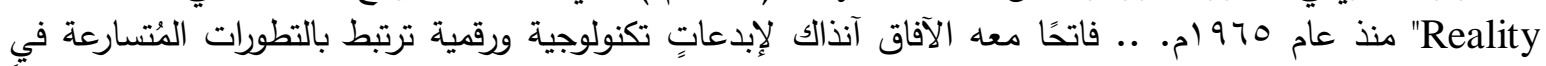

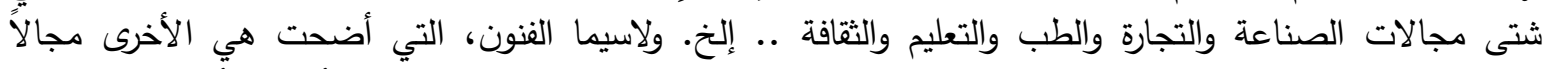

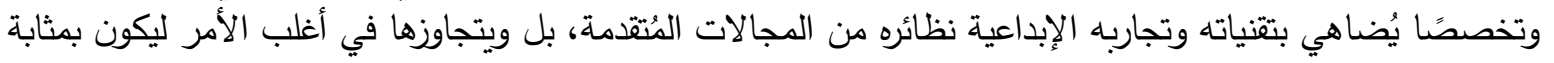

القاطرة والقوة الدافعة لمستقبلٍ يتطور كل لحظة.

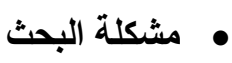

ـ هل يُكن اعتبار الوسيط الرقمي للواقع الافتراضي مجالاً جديدًا ومُبتكرًا لإبداعات فنون الرسم الرقمي؟

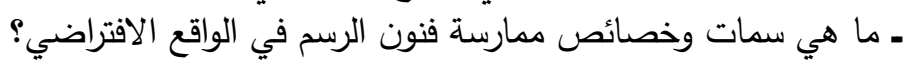

(1) https://www.alukah.net/literature_language/0/5427/ بتاريخ 10 فبراير 9 1. بم.

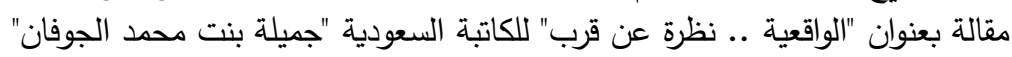

وقع =و http://www.baheth.info/all.jsp?term

(3) https://www.alukah.net/literature_language/0/5427/

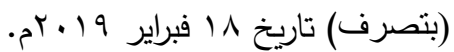

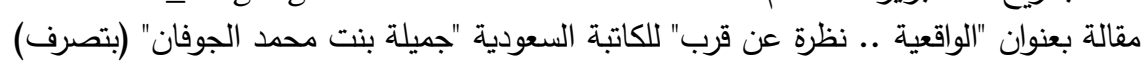

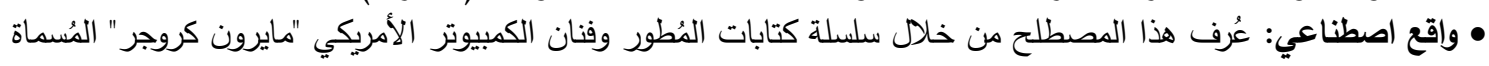
بالواقع الاصطناعي 1965م. 
ـ كيف يمكن للتقنيات التكنولوجية الحديثة من أجهزة وبرمجيات أن تُساهم في تبلور الرؤية الأبداعية لفنون الرسم الرقمي

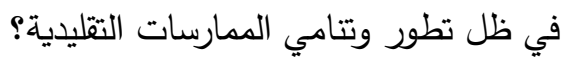

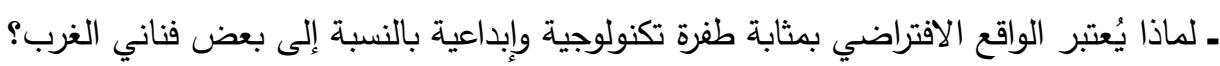

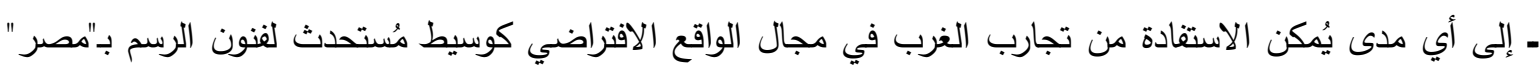
وبالمنطقة العربية؟ أهمية البحث العثية

ـ كان ولا زال وسيظل الرسم مهارةً وتقنيةً وأسلوبًا حجر الزاوية في العمل التشكيلي عامةً وفي العمل الجرافيكي خاصةً

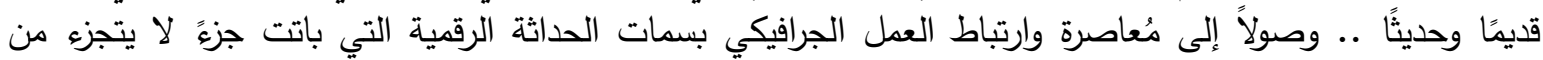

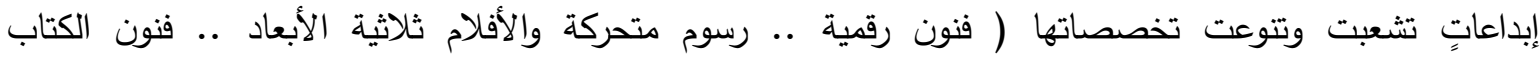

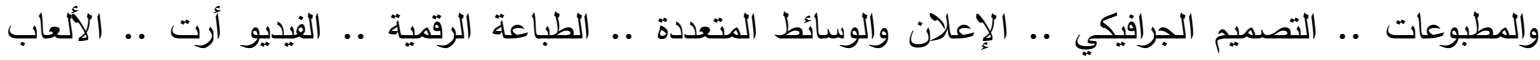

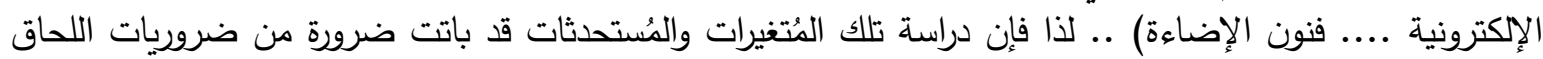
بذلك النمو المُتسارع لفنون الجرافيك عامةً ولفنون الرسم الرقمي خاصةً. هدف البحث النما ـ محاولة إلقاء الضوء على المشروعات الإبداعية الناشئة بالغرب في مجال الرسم الرقمي من خلال الواقع الافتراضي،

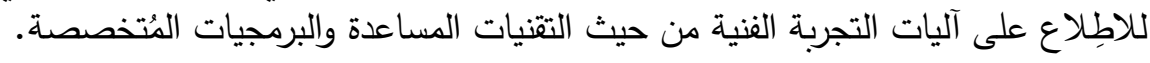

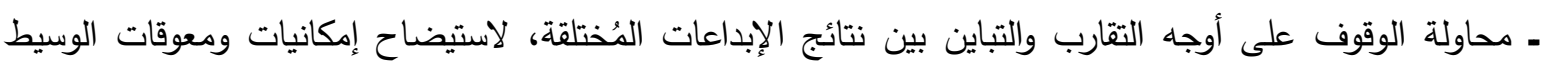
الفراغي كمادةٍ إبداعية مُبتكرة.

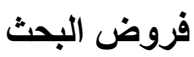

ـ لم تكتمل بعد تصورات ممارسات فنون الرسم أو مُخرجات الإبداع المُتولد من الممارسة في الواقع الافتراضي .. نظرًا

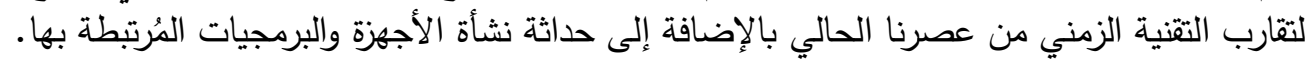
حدود البحث

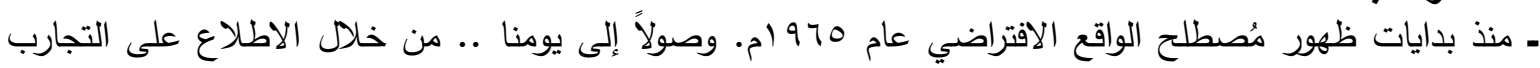
الغربية وخاصة الأمريكية وذلك نظرًا لأسبقية مشروعات شركاتهات الافرا ذات الصلة بموضوع البحث.

منهج البحث

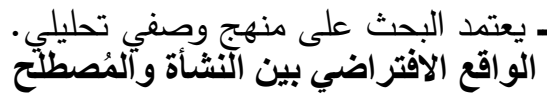

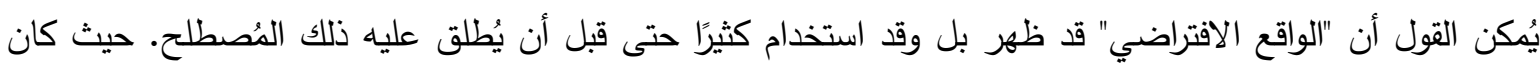

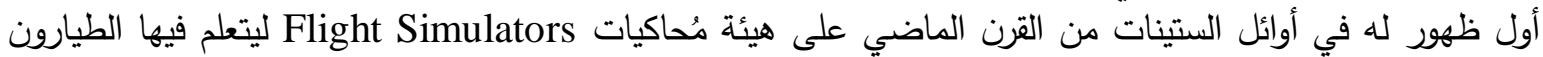

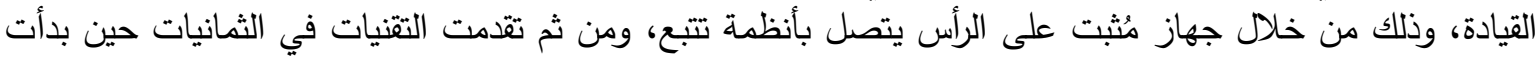

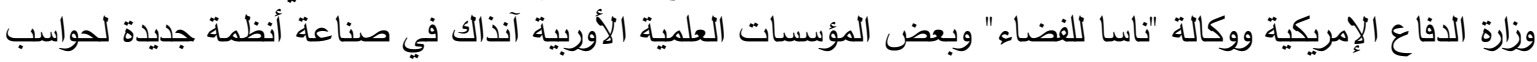

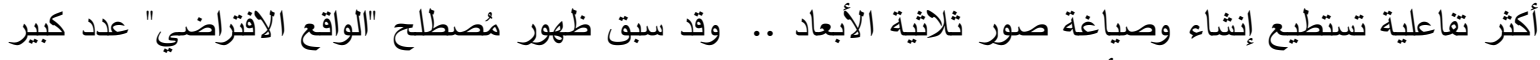

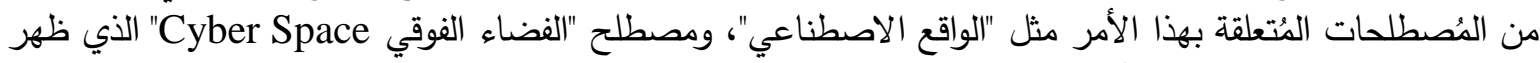

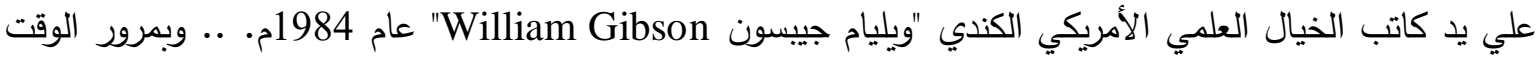

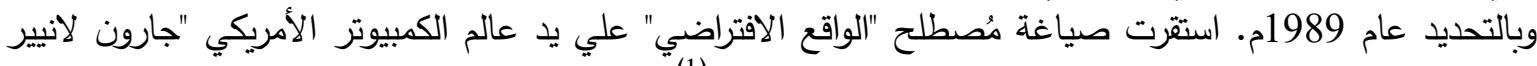

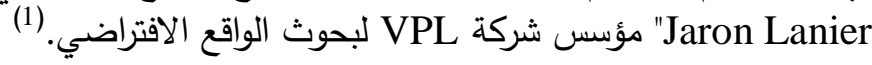
مفهوم الواقع الافتراضي يُقصد بها (( التمثيل شبه الواقعي للأشياء والأجسام والأشخاص وبيئات تواجدها مُضافًا إليها فكرة التفاعلية الدائمة بين

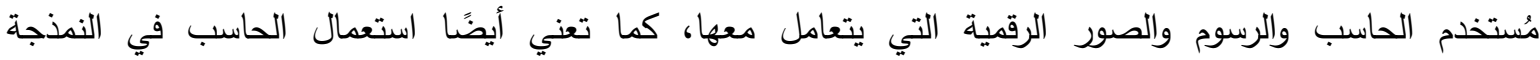
والمُحاكاة التفاعلية Modeling اصطناعية Synthetic أخري حسية أو بصرية ثلاثية الأبعاد، بجعل المُستخدم يستخدمها ويعيش معها وبينها بشكلٍ 
ثلاثي الأبعاد ويتعامل معه في الزمن الحقيقي Real-time كأنها أثياء حقيقية موجودة علي أرض الواقع.()) (1) الأمر

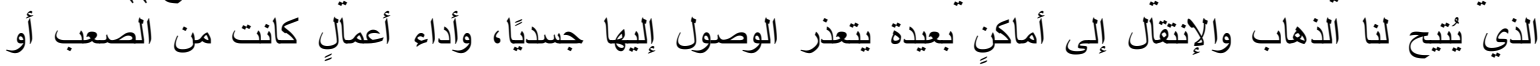

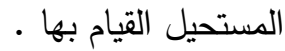

• وبناءًا على ماسبق يمكن استتناج عدة أشياء تُميز ذلك الواقع المُستحدث من خلال تلك البيئات الرقمية القابلة للتفاعل نذكر منها ما يلي: •قدرته على صياغة أشكال وعوالم ثُلاثية الأبعاد، يُمكن لها أن تُحاكي قوانين الإدراك الحسي للإنسان في عالمنا •تمكنه من الاستجابة والتفاعل مع المُستخدم بما يُشبه استجابة الأشياء المُحيطة بنا للفعل الحركي في واقعنا المادي

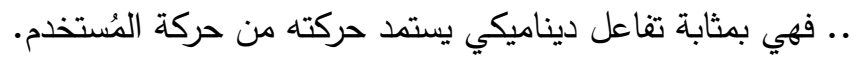

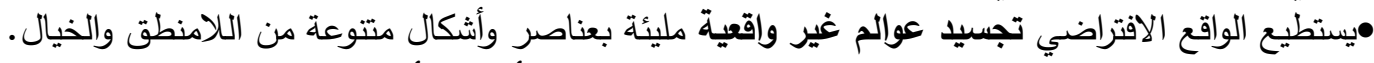

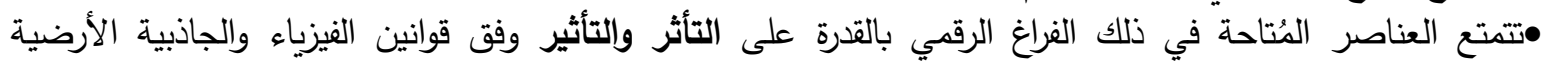

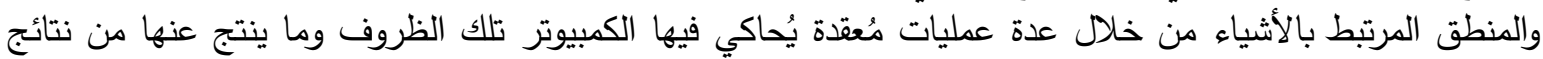
•قابلية وسرعة الاستجابة الفورية لفعل المُستخدم .. وبالتالي فهي تتوافق مع الفعل والزمن اللازمين لددوث رد الفعل

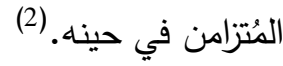

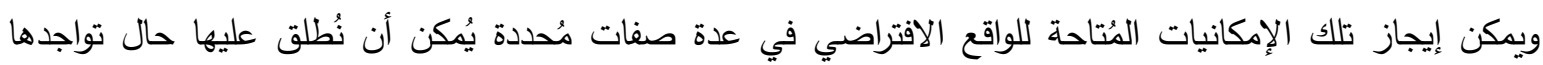
مُجتمعة بأنها سمات أو خصائص تُحدده عن غيره من تقنيات التفاعل الرقمي. سمات الواقع الافتراضي

Immersion الانغراس (1)

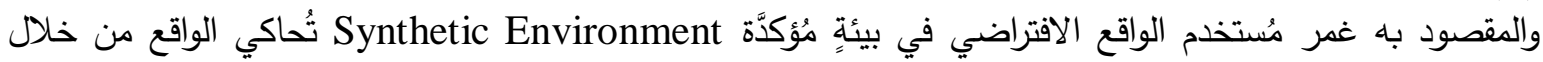

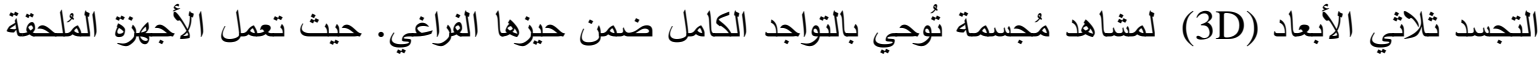

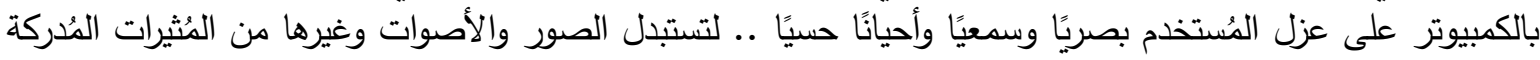

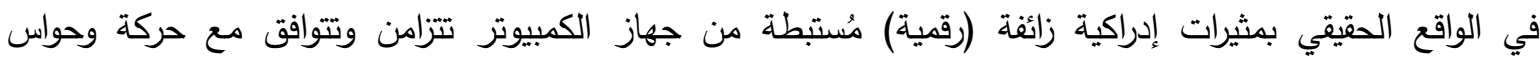

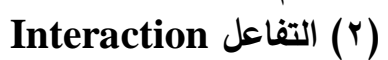

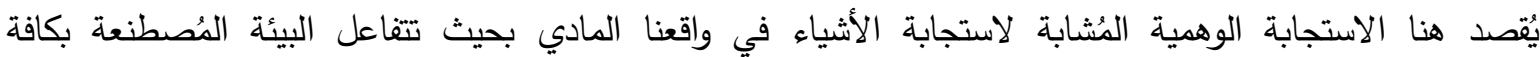

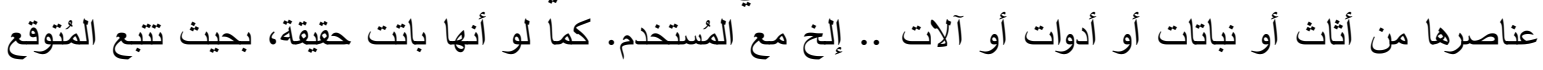

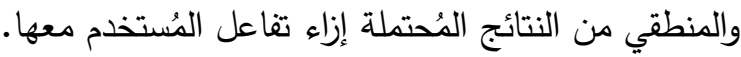

Simulation المُحاكاة

تتمتع تلك الأنظمة بقدرة فائقة علي مطابقة الواقع بكافة تفاصيله وبناءة البصري بثكلٍ يُشبه الواقعية الفوتوغرافية ..

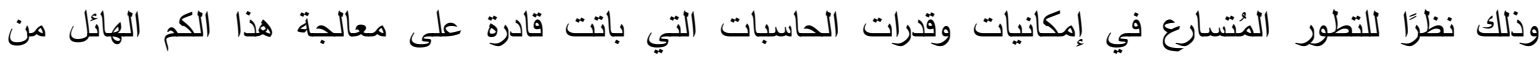

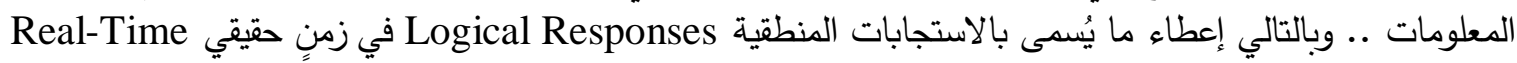

Interactivity (4) التفاعلية

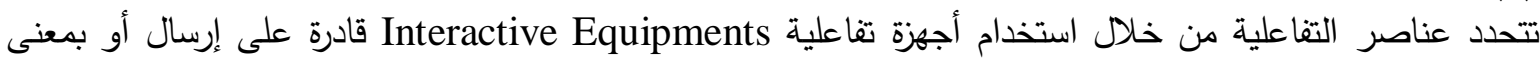

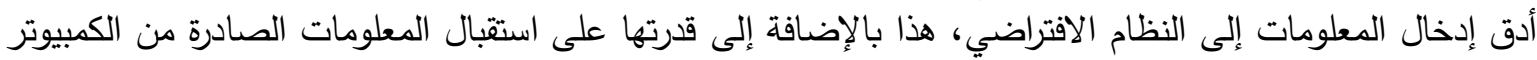

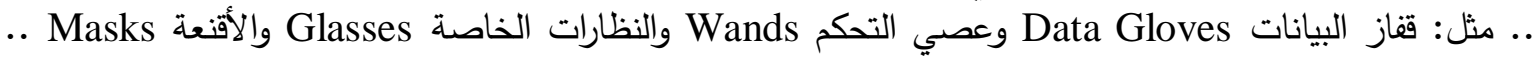

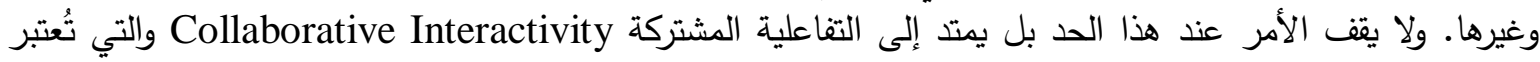

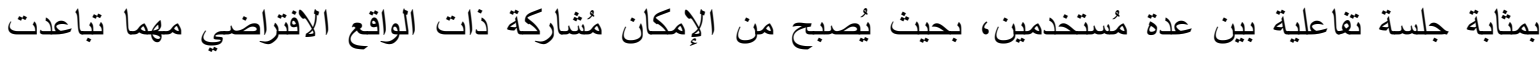


أماكن أقامتهم وذلك من خلال شبكة الأنترنت. ليبدو كل منهم للآخر في صورة شخصية افتراضية مع احتفاظ كلٍ منهم

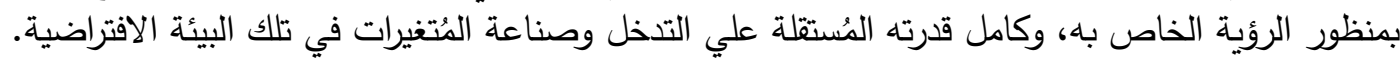

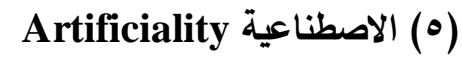
تعتبر قدرة الفنانين والمصممين والمبرمجين على مطابقة الواقع حرفيًا من علامات التميز ، إلا أن ما يُصطنع من أثياء

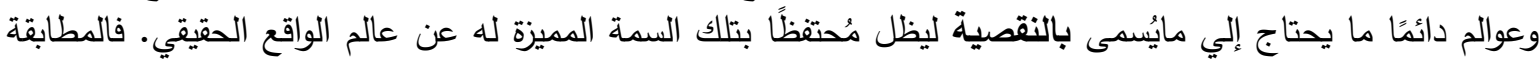

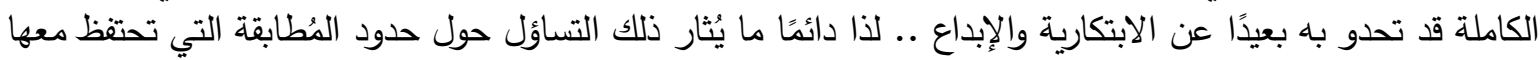
بسمات النقصية البشرية.

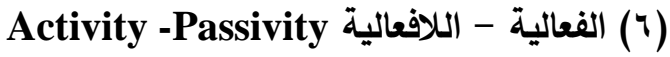

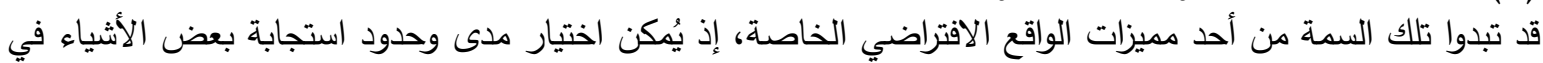

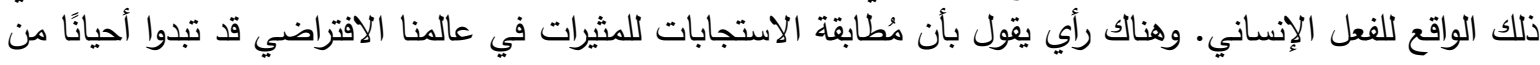

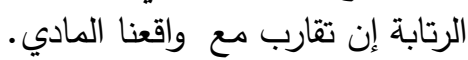

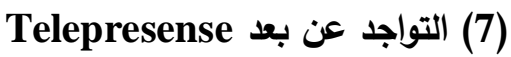
تمثل تلك الخاصية استخدمًا هامًا في عدة مجالات مثل : العمليات الجراحية والاكتثافات الأثرية .. وغيرها. حيث تُككن

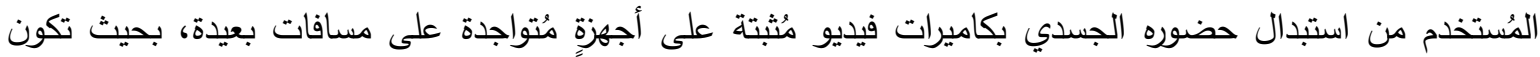

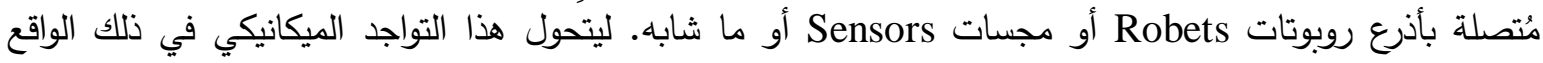

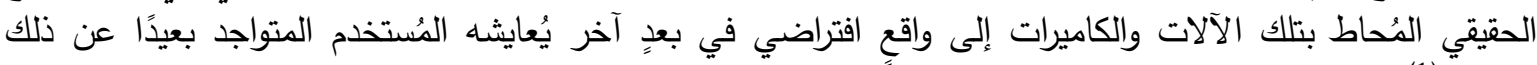

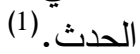

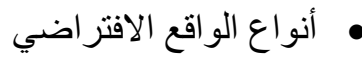

(1) (1) واقع افتراضي طرفي.

ويعمل هذا النوع من خلاّل الثاشات العادية لاستعراض الواقع الافتراضي حيث لاتزال عين المُستخدم تُدرك الواقع الحقيقي الدُحيط بإطار شاشة العرض العان. (r) واققع محدود الوظيف والمكان.

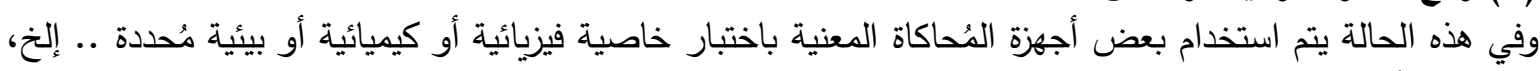
وذلك استباقًا لنتائج التجربة الحتئة الحقيقة. (r) واقع افتراضي كامل التواجد.

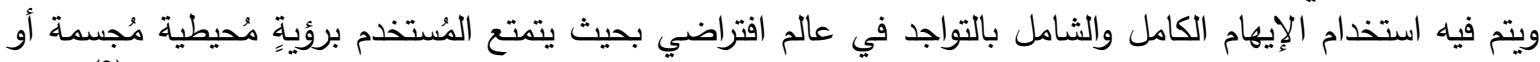

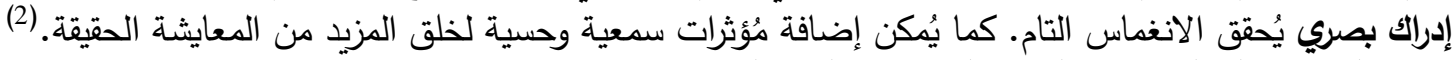

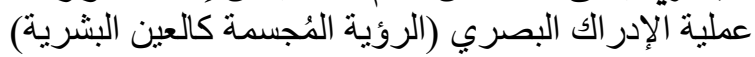

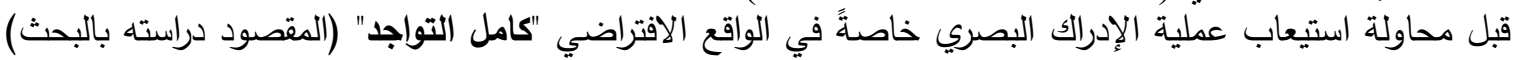

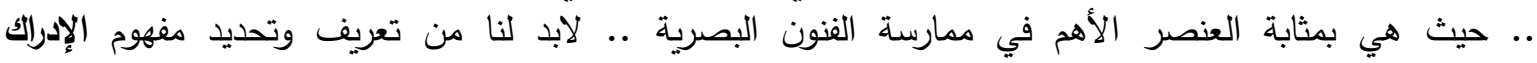
Perception

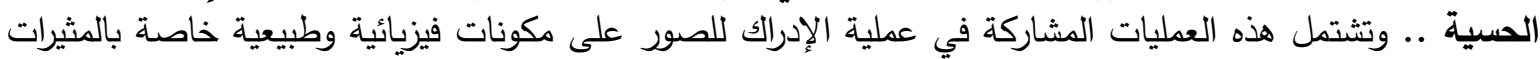

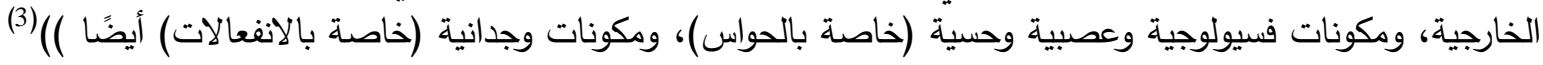

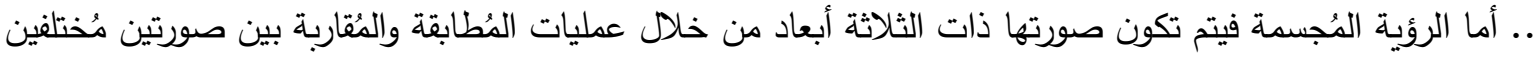

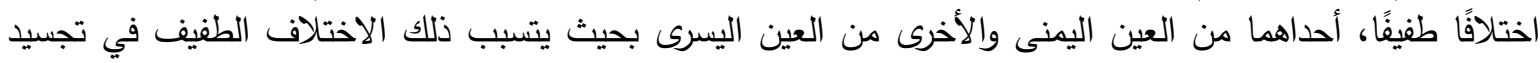

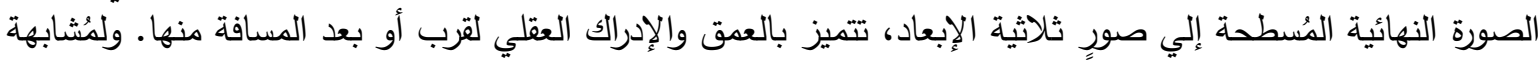

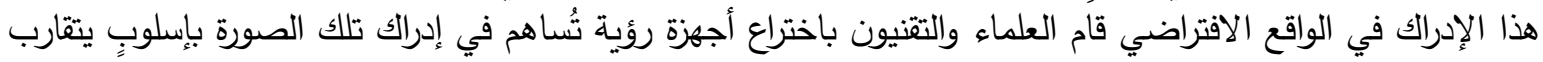
فهمه مع إدراك الرؤية البصرية المباشرة.

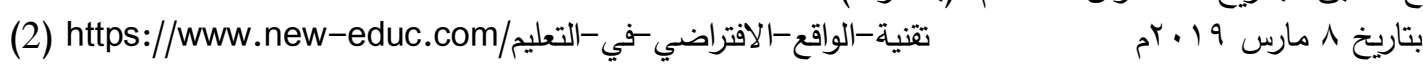

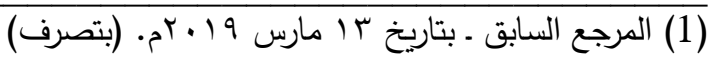

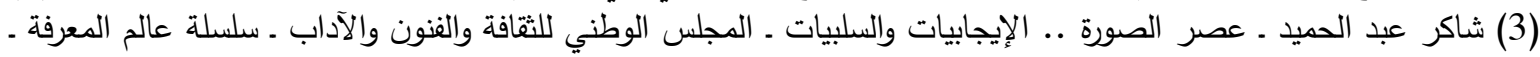

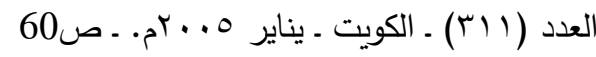




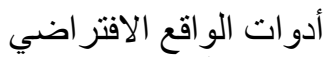

$$
\begin{aligned}
& \text { يمكن إيجاز أجهزة ومعدات الواقع الافتراضي في جزئين هما }
\end{aligned}
$$

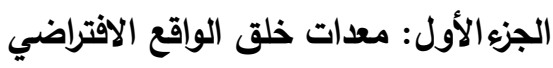

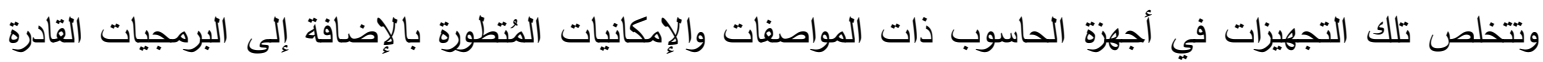

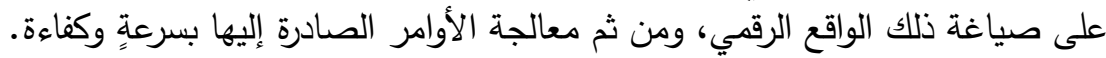

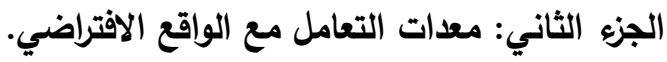

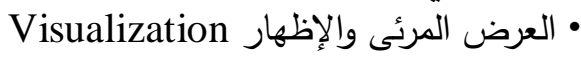

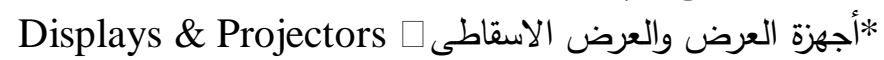

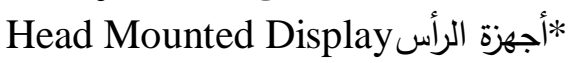

• التجوال والاستكثاف Navigation

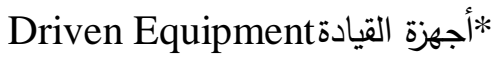

Mounted Equipmentكأجزة التوجيه المتحرك

Control \&Touch

Grasp التناول والقبض

• ت تبع الوضع Tracking Position

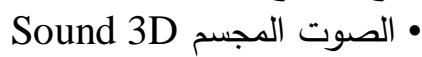

•تقنيات الحقيقة المضافة Augmented Reality

$$
\text { • ب دور الوسيط في العملية الإبداعية }
$$

بما أن الوسيط أو ما يُسمى بالخامة هو أحد أضلاع عناصر العمل الفني الثلاث ( المادة ـ الموضوع ـ التعبير) ولإدراك

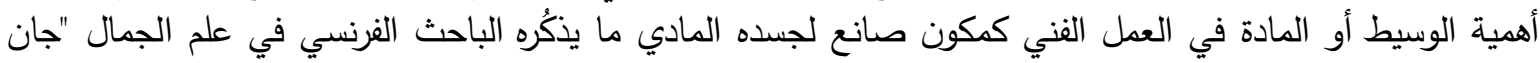

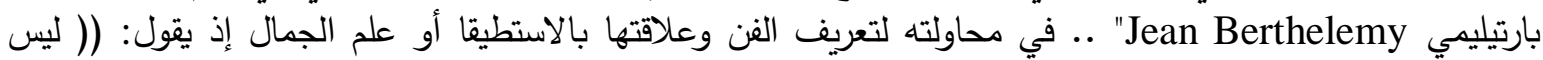

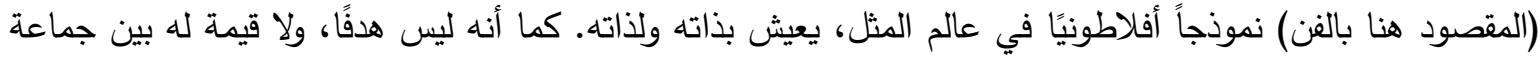

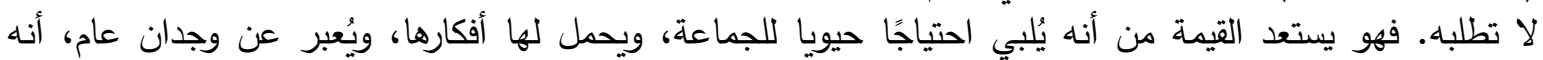

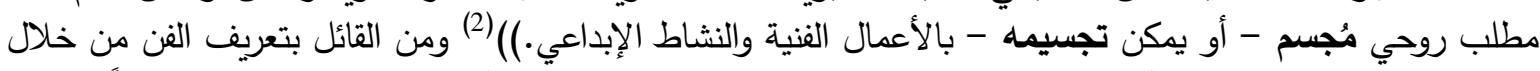

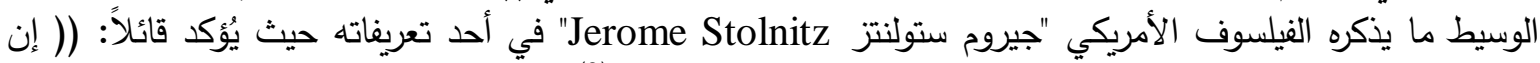

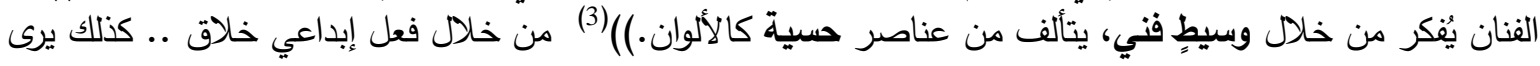

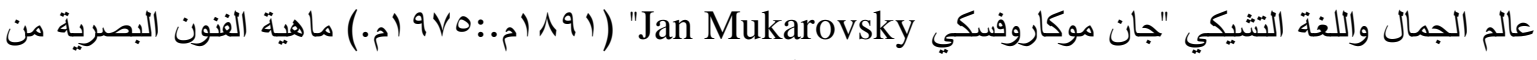

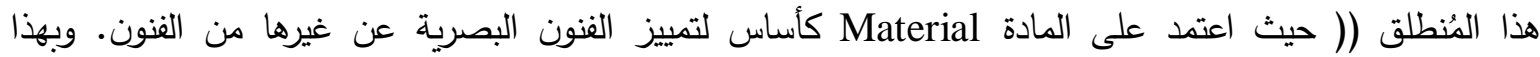

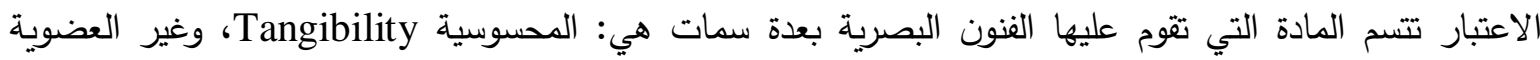
Inorganic، وغير القابلية نسبيًا للتغير Unchangeable Matter.

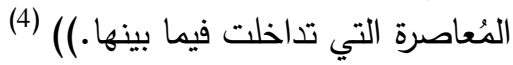

. فدائمًا ما يبحث مُبدعو الفنون وخاصةً التشكيلية منها عن كل ماهو مُبتكر رغبةً منهم في درء الملل الناتج عن تكرار

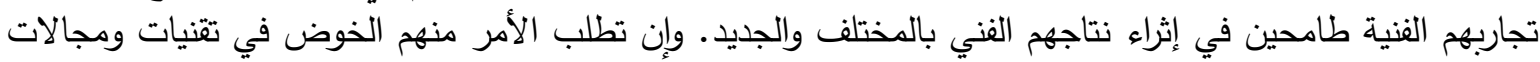
مُستحدثة لم تعهدها خبرتهم وتجاربهم السابقة، لذا فقد كانوا في طليعة من أخضعوا الكمبيوتر منذ نشأته في إبداعهم

(1) http://www.ergo-eg.com/ppt/2vrb.pdf

بتاريخ r ا مارس 9 1. بم.

(2) مختار العطار ـ الفنون الجميلة بين المتعة والمنفعة ـ الهيئة المصرية العامة للكتاب بالتعاون مع الجمعية المصرية للنقاد - دراسات في

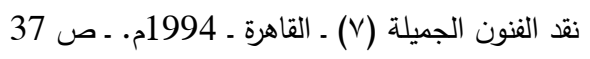

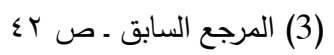

(4) ماهر عبد الححس ـ جماليات الصورة في السيميوطيقا والفينومينولوجيا ـ الهيئة العامة لقصور الثقافة ـ سلسلة الفلسفة (بال) ـ الطبعة

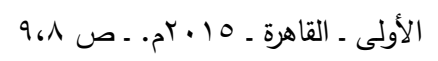




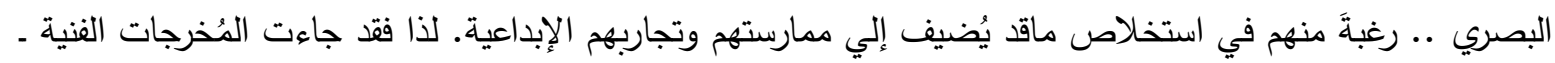

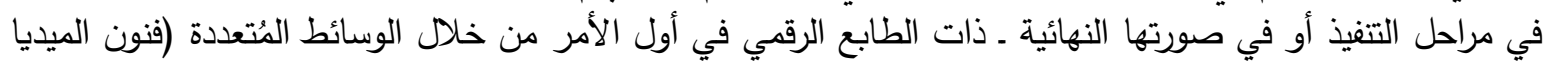

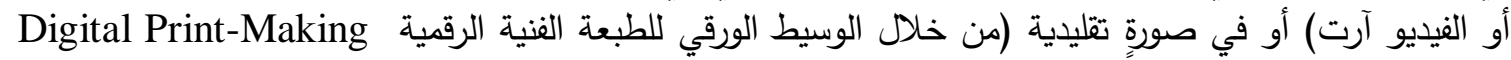

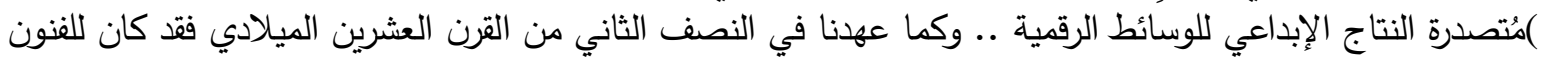

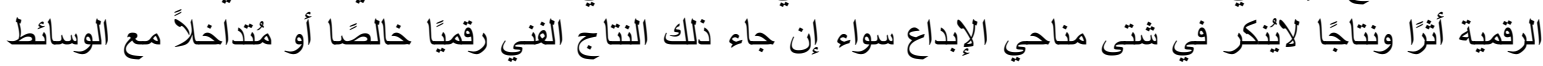

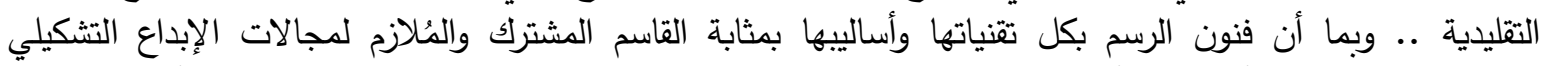

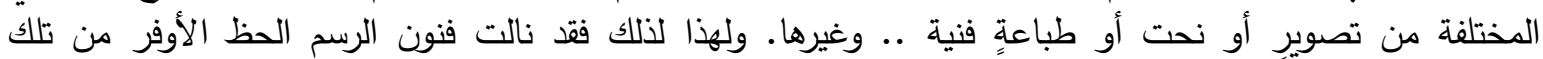

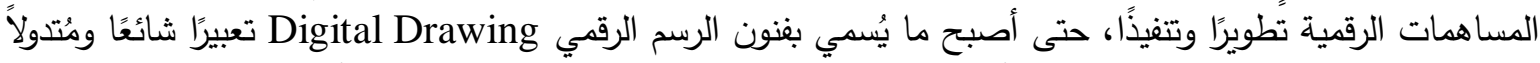

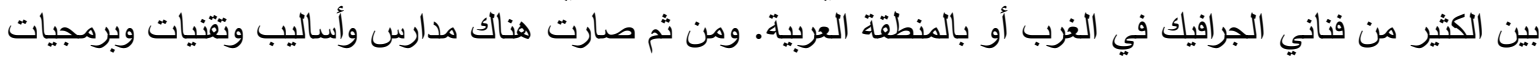

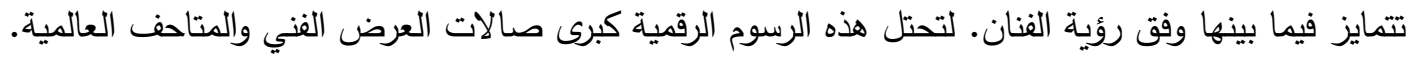

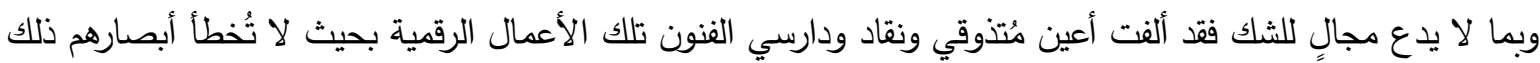

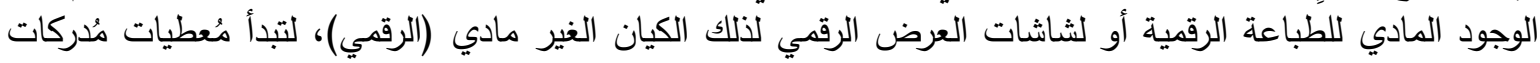

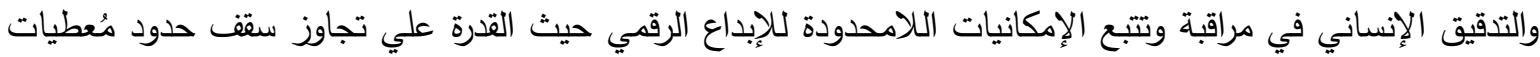

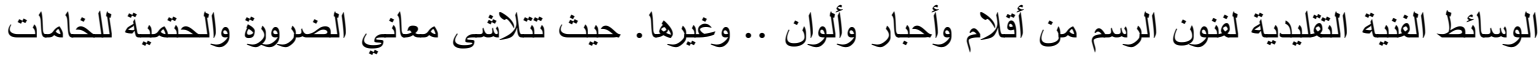

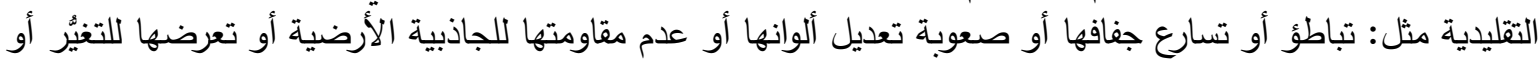
التلف بفعل العوامل الجوية أو عدم قدرة رغبة أوفا الفنان في حذف أو تعديل العمل الفني.

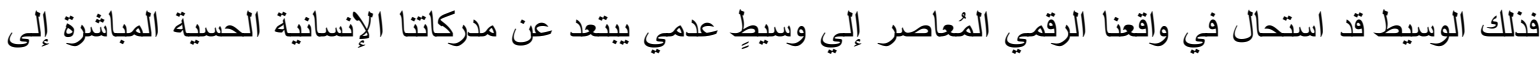

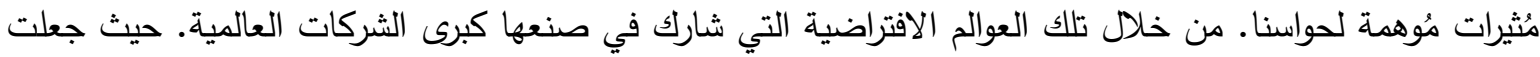

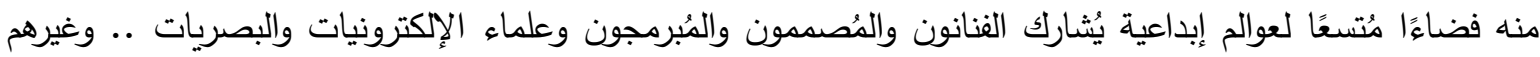

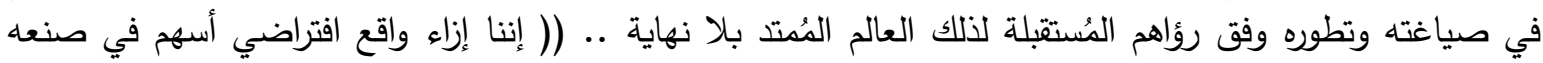

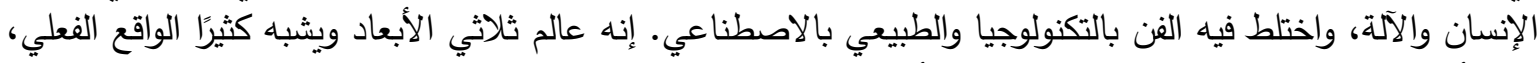

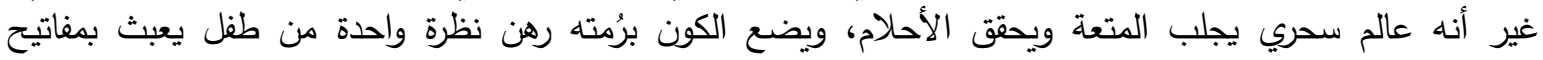

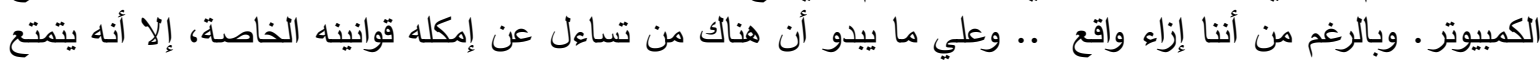

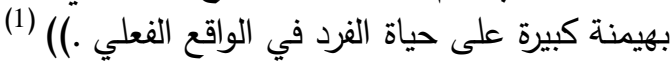

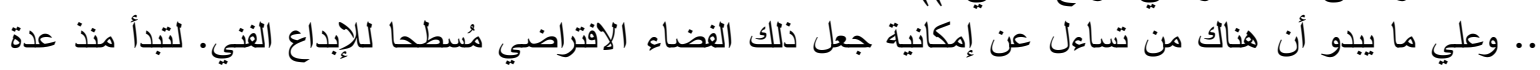

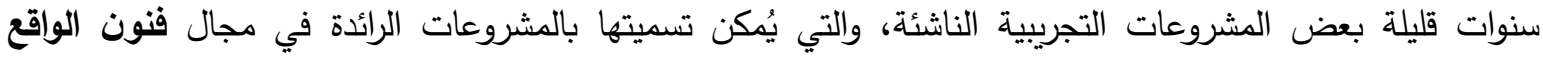

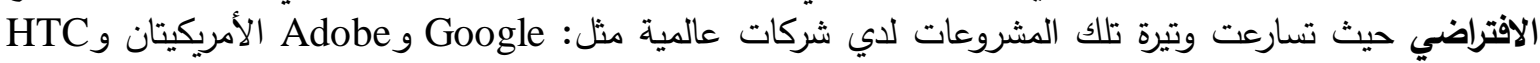
التايوانية .. وغيرهما الكثير .

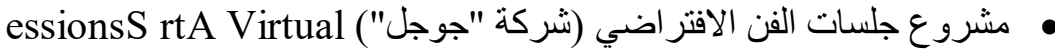

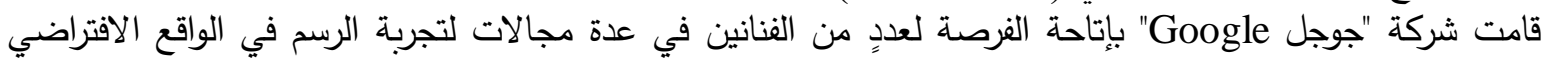

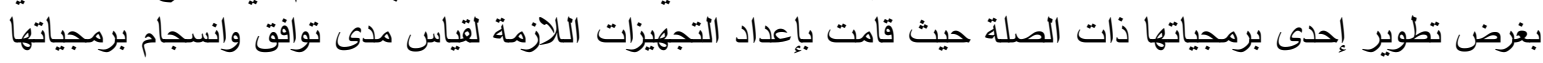

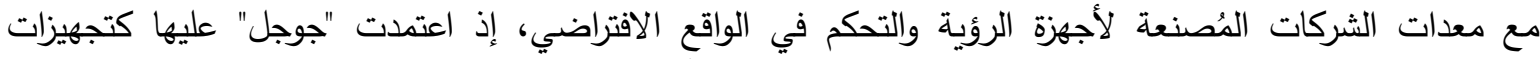

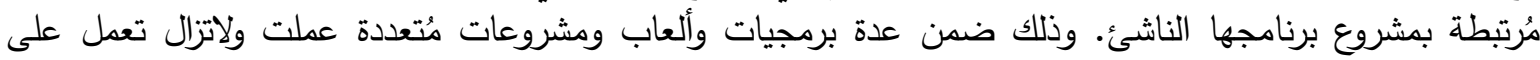
تطويرها ضمن مجال الواقع الافتراضي .. كانت البداية منذ حوالي عام 2016م. بونلاية "سان فرانسيسكو" الأمريكية

استضافت سبعة فنانين لاختبار الرسم ثلاثي الأبعاد في الواقع الافتراضي من خلال برنامجها Tilt Brush وهم:

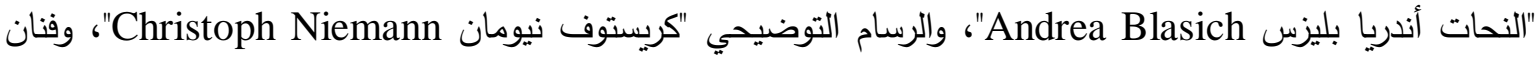

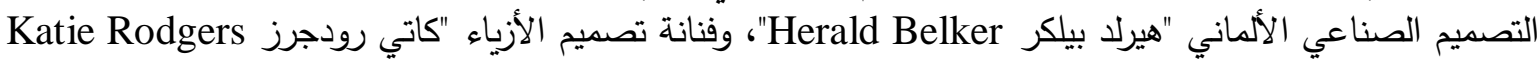

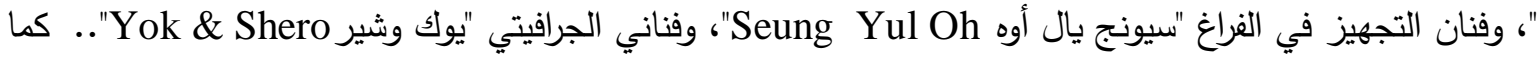

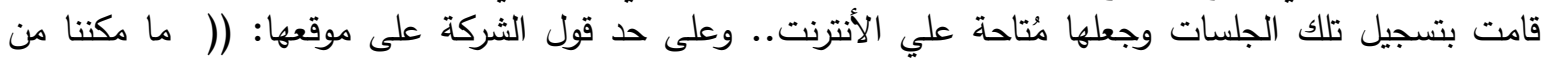


متابعة الفنانين وهم يطورون إبداعاتهم في الواقع الافتراضي من أي زواية نرغب.))(1) (( كما اتاحت لمُستخدم الموقع

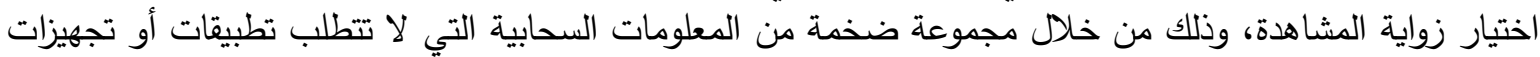

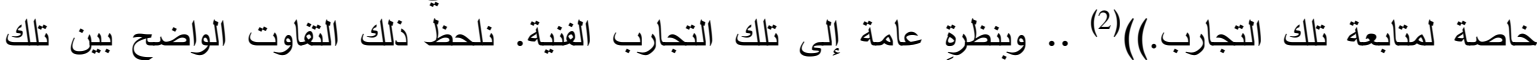

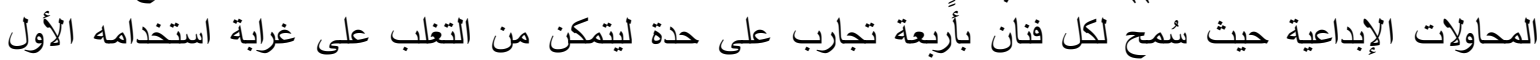

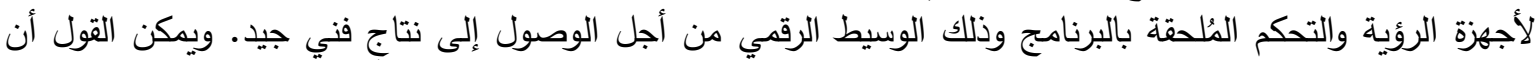

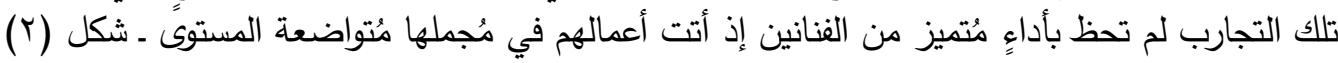
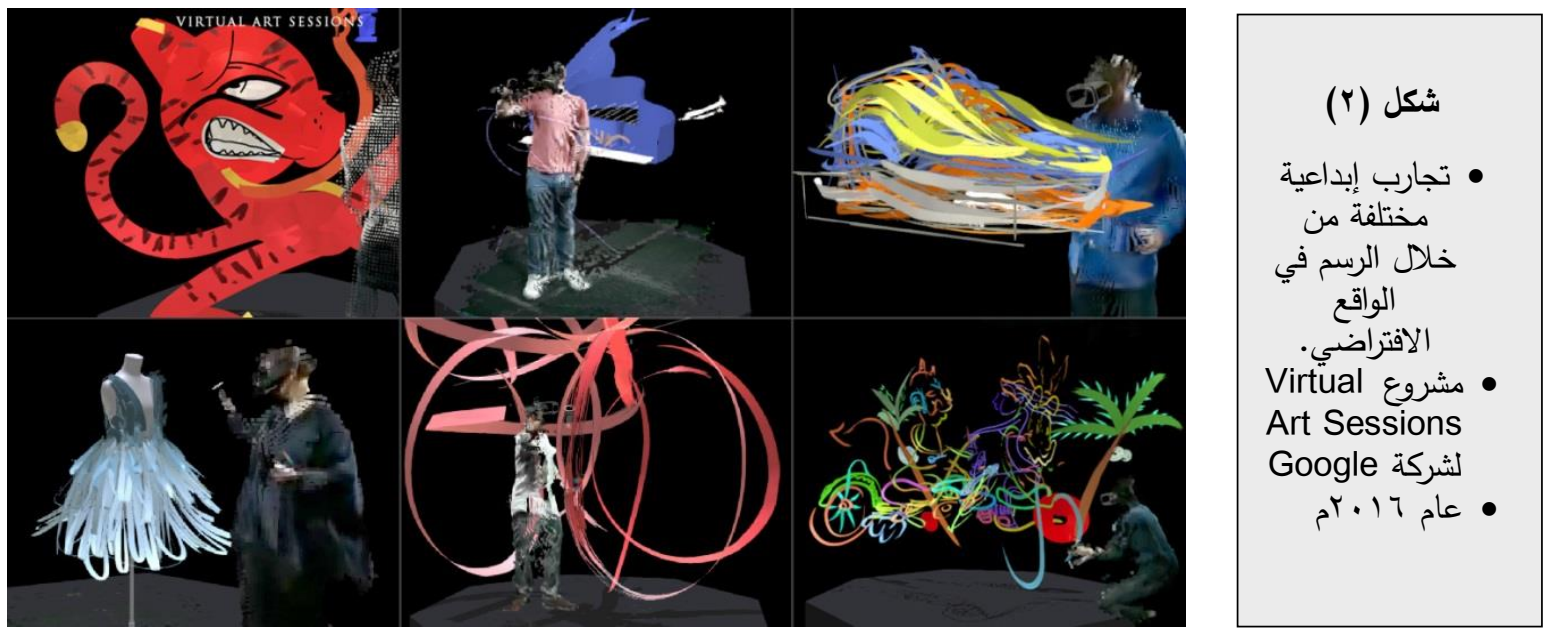

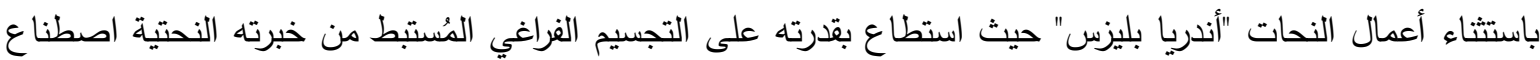

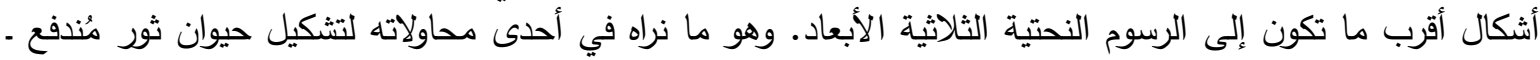

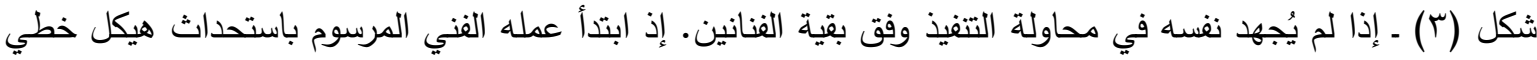

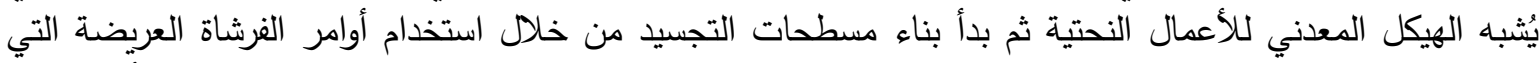

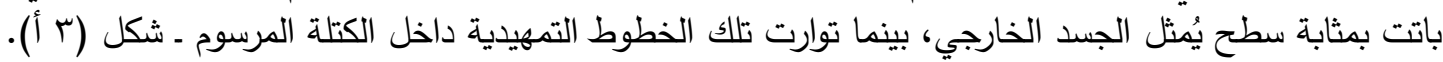
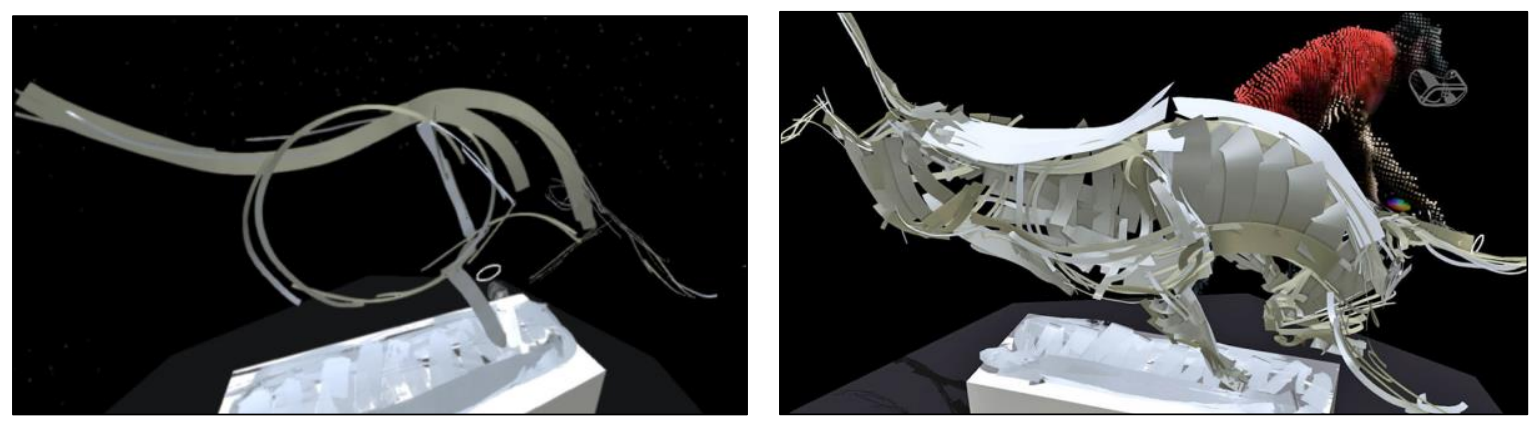

شكل (بأ) هيكل تمهيدي لرسم ثور مُندفع للفنان

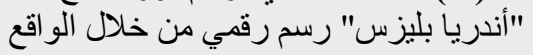

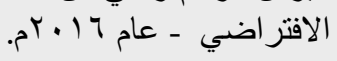

شكل (rارسم ثُور مُندفع للفنان "أندريا بليزس" . . رسم

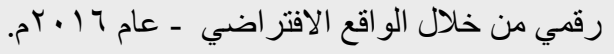

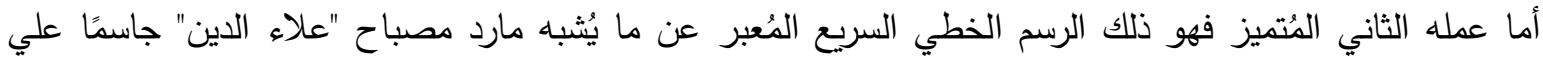

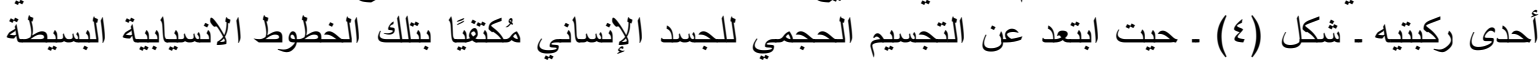

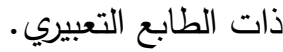

(1) https://virtualart.chromeexperiments.com/\#/tech

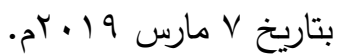

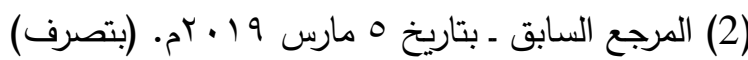




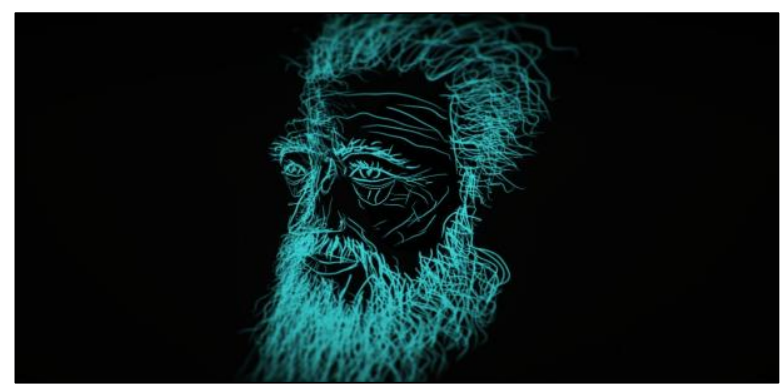

شكل (5)

• رسم لوجه رجل عجوز للفنان الفرنسي "أتما"

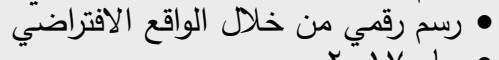

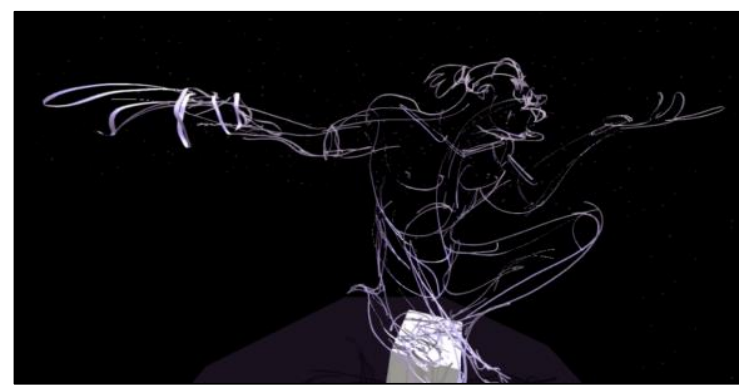

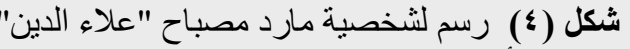

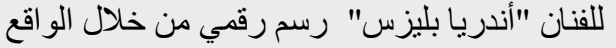

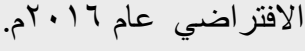

ويمكن تفسير ذلك التميز في الأداء إلي طبيعة الفنان السابقة كنحاتٍ يستطيع إدراك مُعطيات البعد الثالث وإشكالية

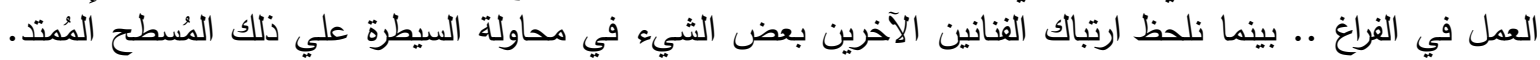

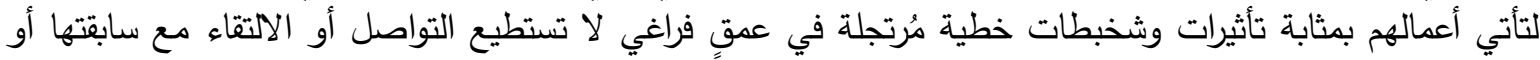

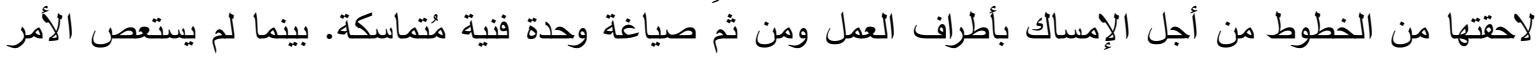

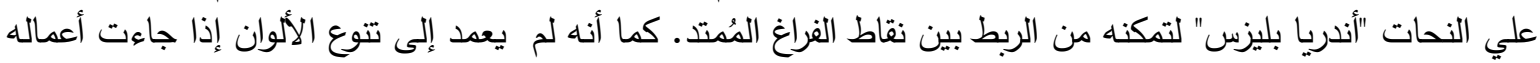

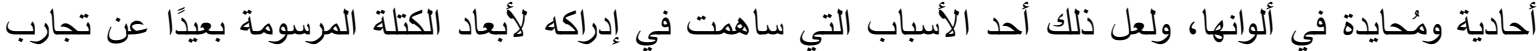

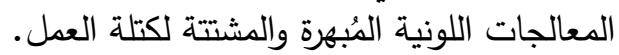

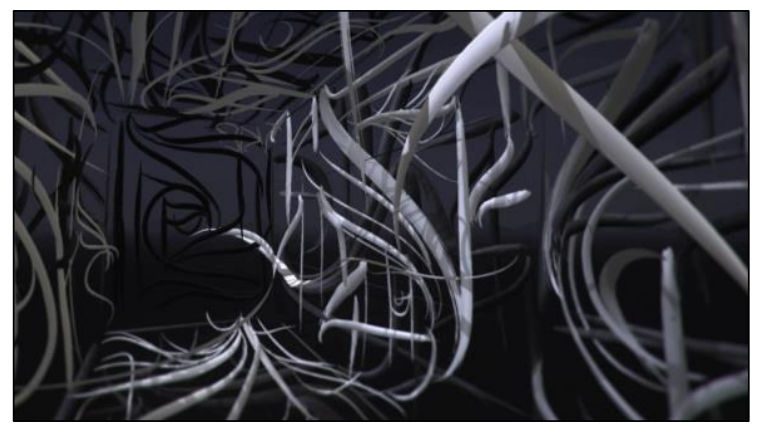

$$
\text { • برنامج الفنان المُقيم (شركة "جوجل") }
$$

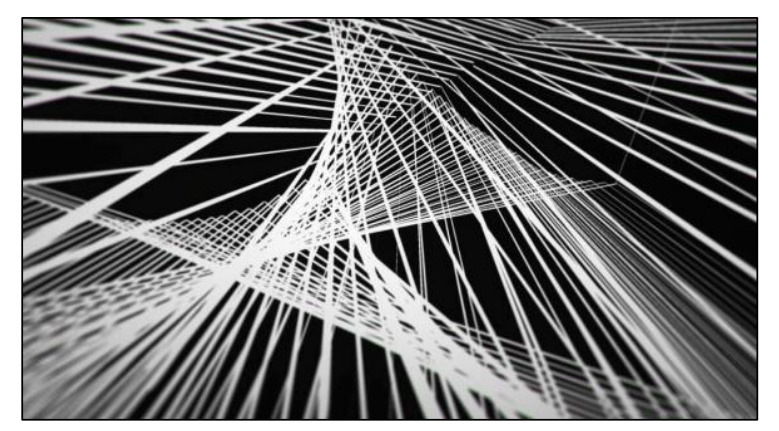

شكل (7) رسم خطوط منظورية للفنان البربطاني

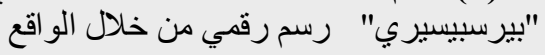

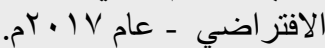

علي ما يبدو أن تلك المشروعات التجريبية الأولي لشركة "جوجل" قد أثارت حماس الفنانين لمزيدٍ من التجارب الفنية في

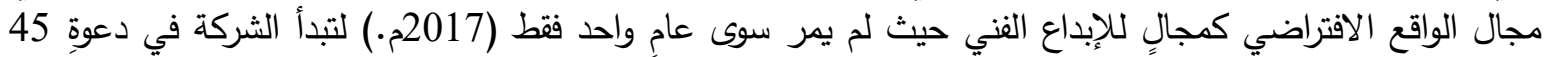

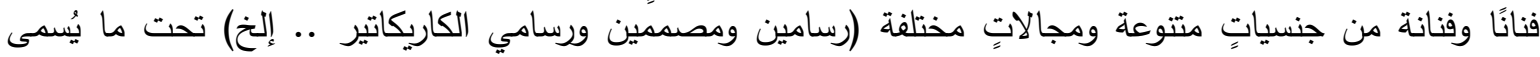
بيرنامج "إقامة الفنان Artist in Residence من أجل تطوير برنامجها الناشيء

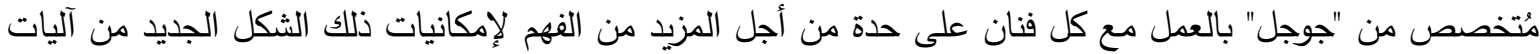

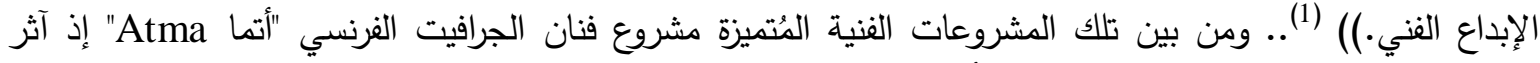

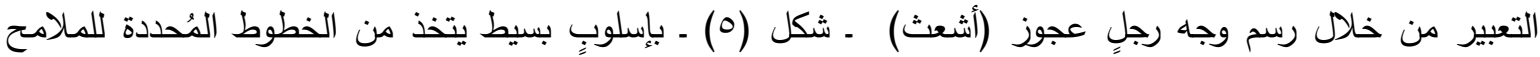
وتقصيلياتها مُنطلقًا للسيطرة على كتلته المرسومة. ليبدوا العمل أقرب ما يكون للأعمال النحتية المُكونة من الأسلاكل 


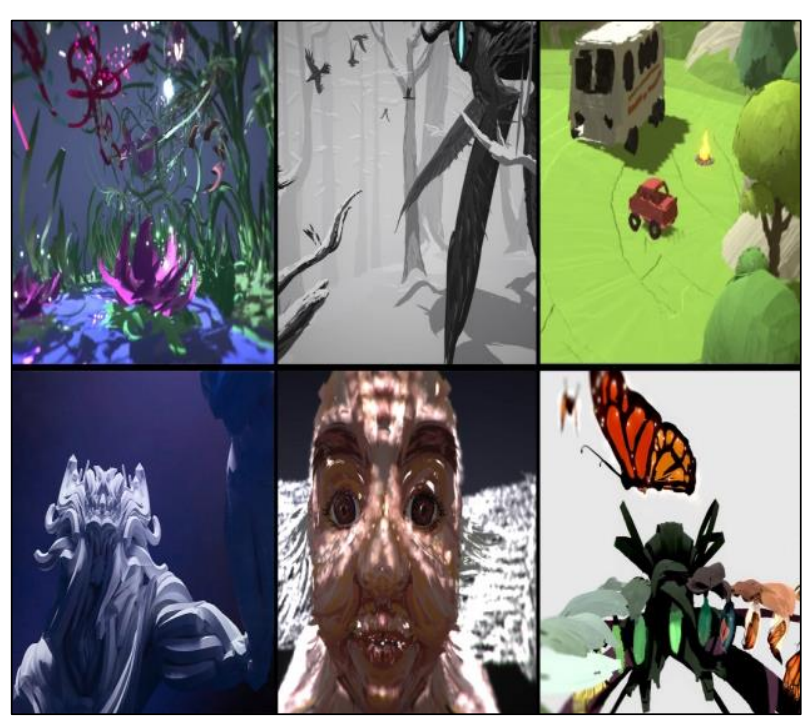

شكل (^)

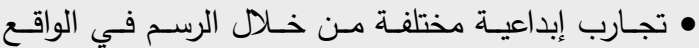
الافقتراضي .. توضح سمات الميل إلميل إلى المحاكاة الوأقعية ..

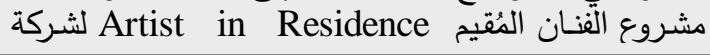

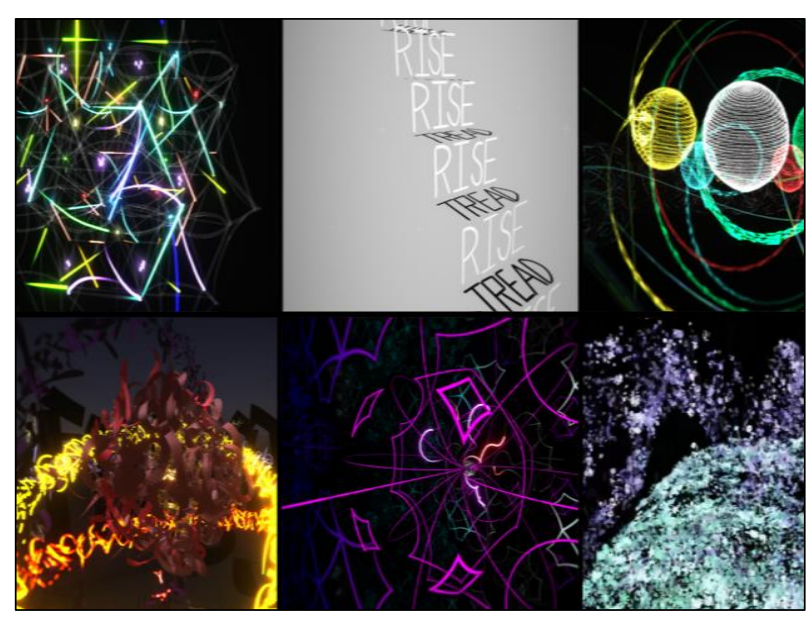

شكل (9)

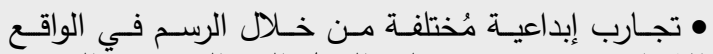
الافقتراضـي توضـح ســات الديـل إلى التجريـب والتعبيـر
ومن الأعمال الغريبة الطابع نتاجًا وتصنيفًا عمل الفنان

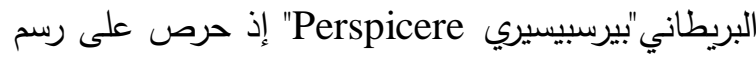
وتشكيل ذلك التراغ الرقمي بخطوطٍ بيضاء شديدة الاستقامة لتتلاقى في عدة نقاط تُشبه نقاط تلاشي خطوط لتشوط

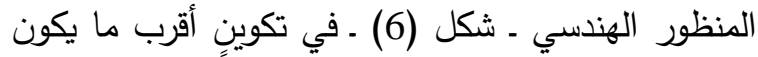

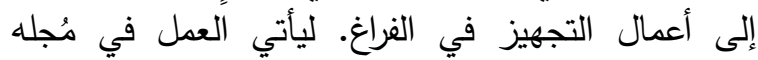

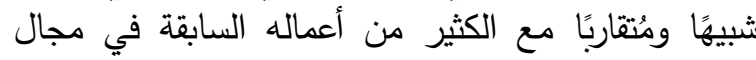
التجهيز في الفراغ (التي يستخدم فيها المسامير والخيوط

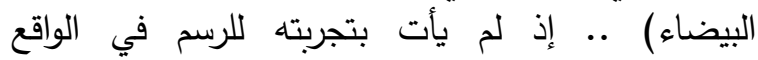
الافتراضي بجديدٍ يُخالف ما عهده من تجارب سابقة.

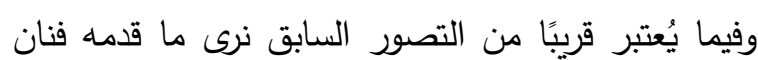

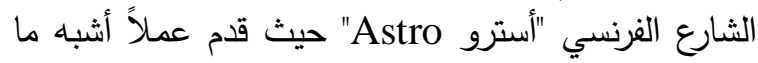

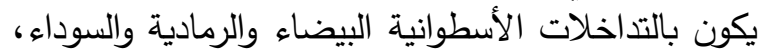

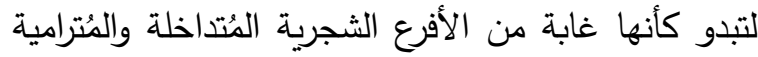
الأطراف ـ شكل (7).

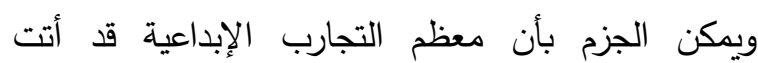

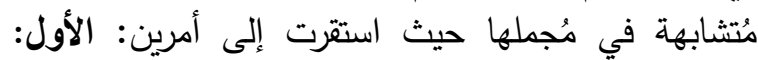
وذلك للفنانين الأكثر ميلاً في أعمالهم إلى الى المُحاكاة

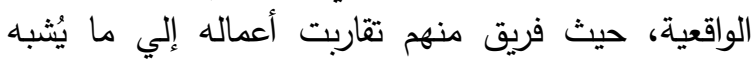

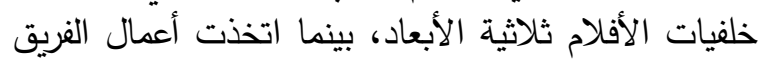

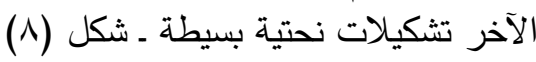

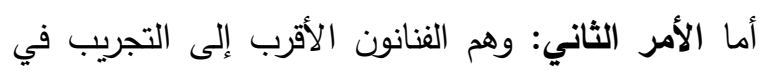
مجالات التجهيز في الفراغ والجرافيتي والفيديو آرت وفئ وفنون

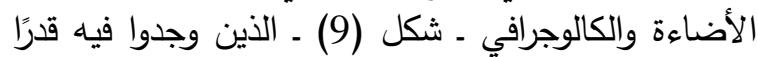

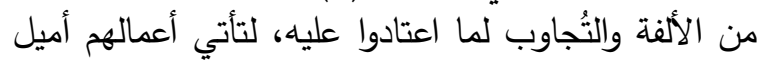

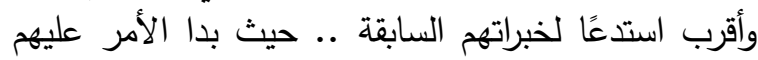

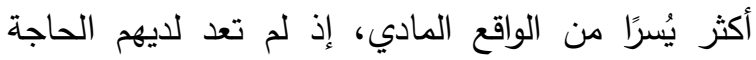

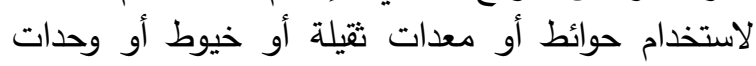

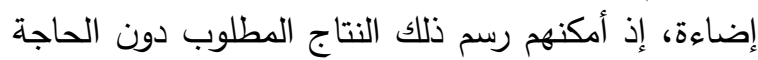

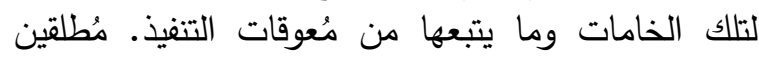

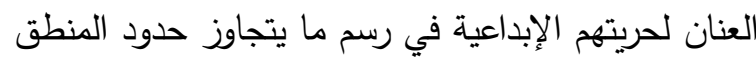
والمُعتاد من وسائط الفنون السابقة فئة

بما أن شركة "جوجل" من كبرى الثركات العالمية المُتخصصة في مُحركات البحث على الأنترنت وإنتاج البرمجيات

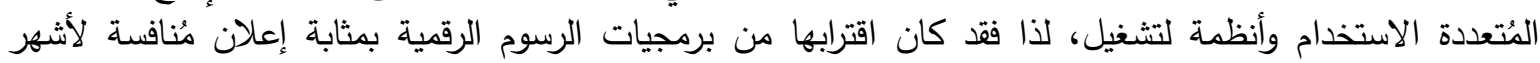

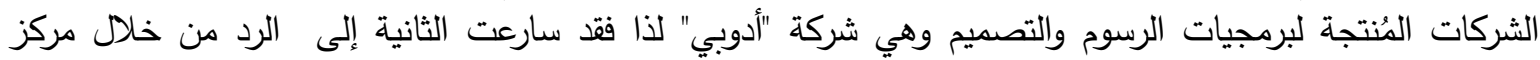

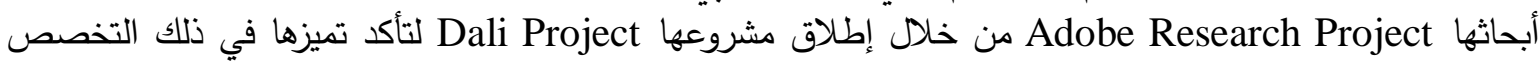

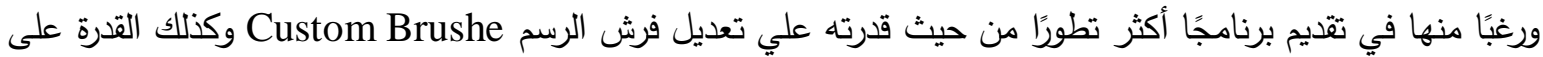

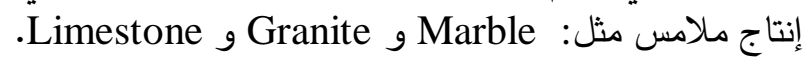
إلا أن تلك الخطوات لاتزال حتى الآن في نطاق الإعداد. إذ لم تُعلن الثركة بعد عن موعد الإصدار في سوق البرمجيات منذ أواخر عام 2016م. وعن مشروع البرنامج يقول "إريك بيتزاكي Erik Natzke" مسؤول إقامة الإنئ الفنانين 
بمركز أبحاث شركة أدوبي الأمريكي Principl Atist- in- Resident at Adobe Research: (( نحن لازلنا في

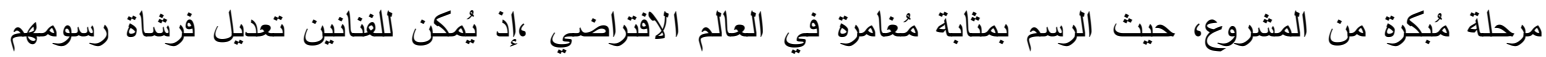

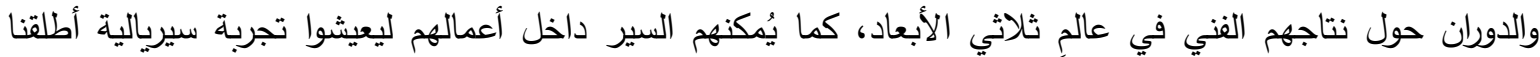

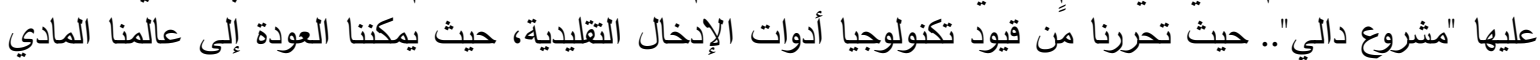

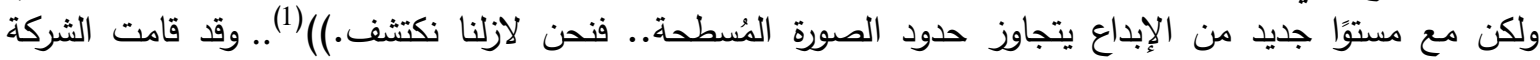

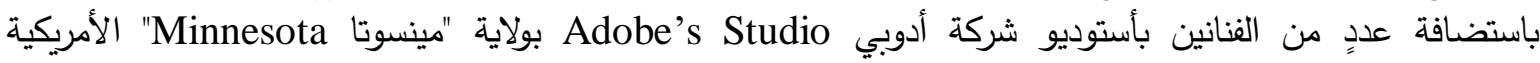

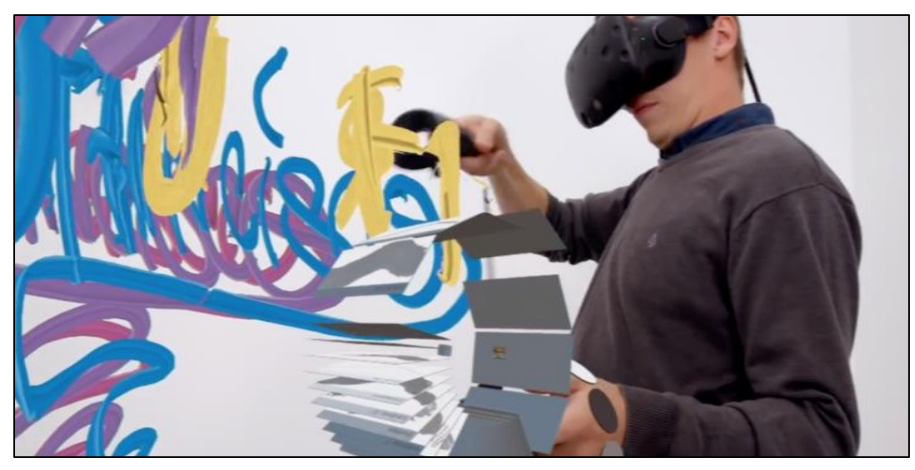

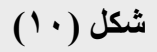

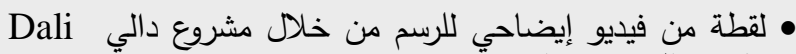
Project

لإعطائهم الفرصة لتجربة الإبداع الرقمي بعيدًا

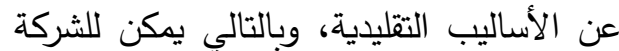

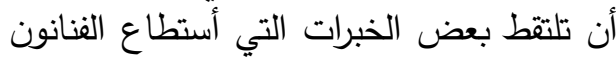

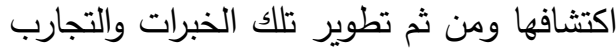

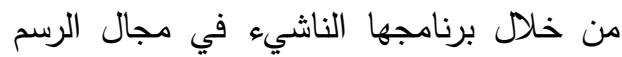
في الواقع الافتراضي - شكل (10) - ويعود "إريك بيتزاكي Erilc Natzke" للحديث قائلاً:

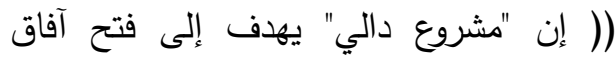
جديدة للفنانين. حيث يمكنهم التحرك برشاقة

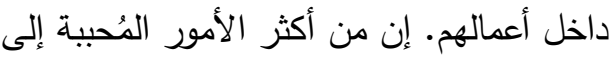
قلبي هي الطريقة التي نرى فيها إنغماس التراس التراس

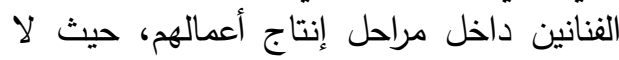

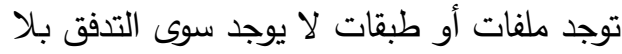

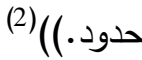

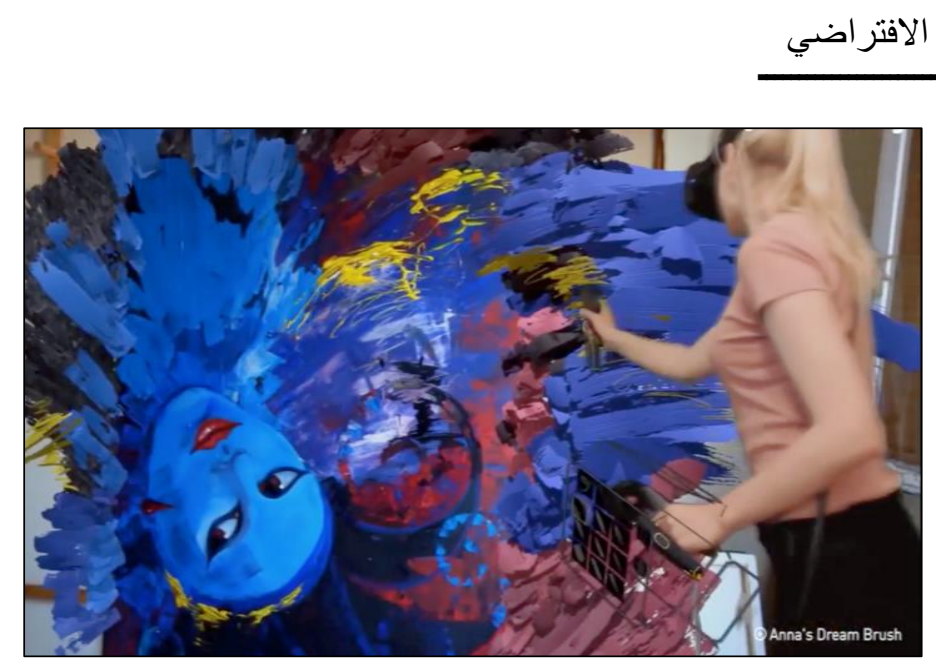

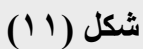

• لقطة من فيديو إيضـاحي يشرح أسلوب الفنانـة الروسية الفرنسية

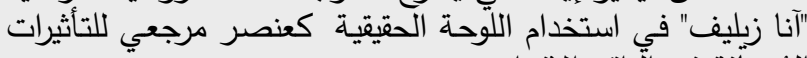

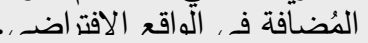

\section{• •}

"Anna Zhilyaeva •

تعمل هذه الفنانة علي الجمع بين الخامات

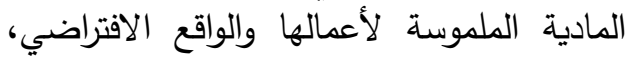
وذلك من خلال برنامج Google's Tilt Brush إذ تقوم بالرسم الافتراضي فوق لوحتها الأصلية بعد إدخال صورة عملها الحقيقي كمرجع للمراحل لإنل المُستكملة في الواقع الفتراضي ـ شكل (11) -

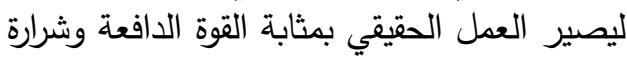
البدء للتأثيرات المُضافة في الواقع الافتراضي.

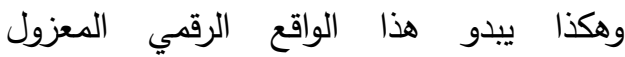

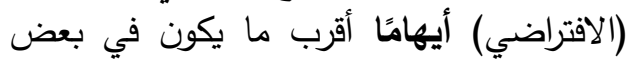

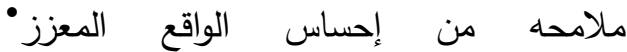
Augmented Reality

(1) https://theblog.adobe.com/project-dali-building-an-endless-creative-canvas-with-virtualreality/

$$
\text { (بتصرف) بتاريخ ^ مارس } 9 \text { 19 ب م. }
$$

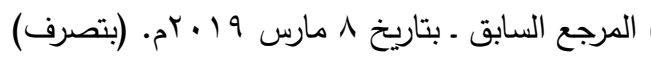

• الواقع المُعزز: هي التكنولوجيا القائعة على إسقاط الأجسام الافتراضية والمعلومات في بيئة المُستخدم الحقيقية لتوفر معلومات إضافية أو تكون بمثابة موجِه له. 
الإحساس بالواقعية المادية. (1) إلا أنه في حقيقة الأمر يظل واققًا افتراضيًا كما هو

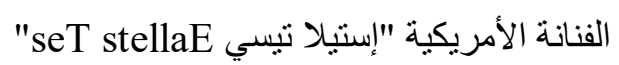

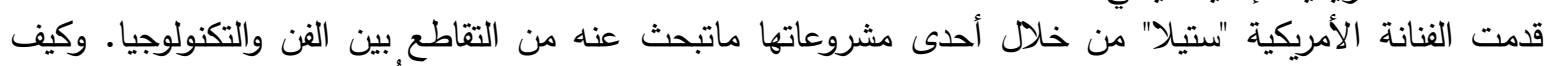

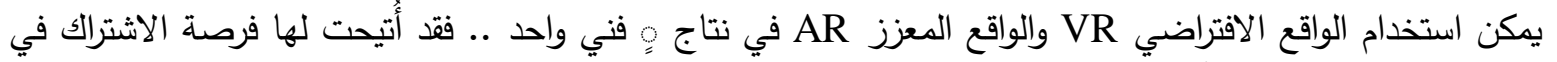

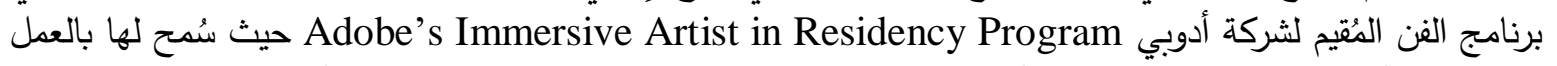

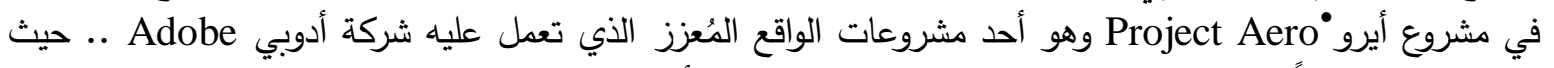

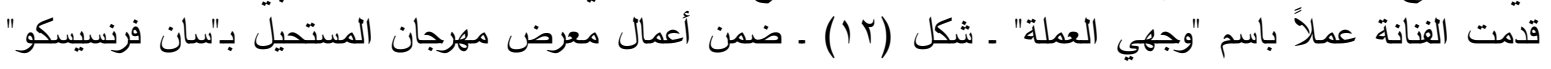
موضوع موضوع على قاعدة خشبية بقاعةٍ صغيرة فارغة داخل صالة العرض بينما يُمسك المشاهدون بأجهزة لوحية مثل: iPad
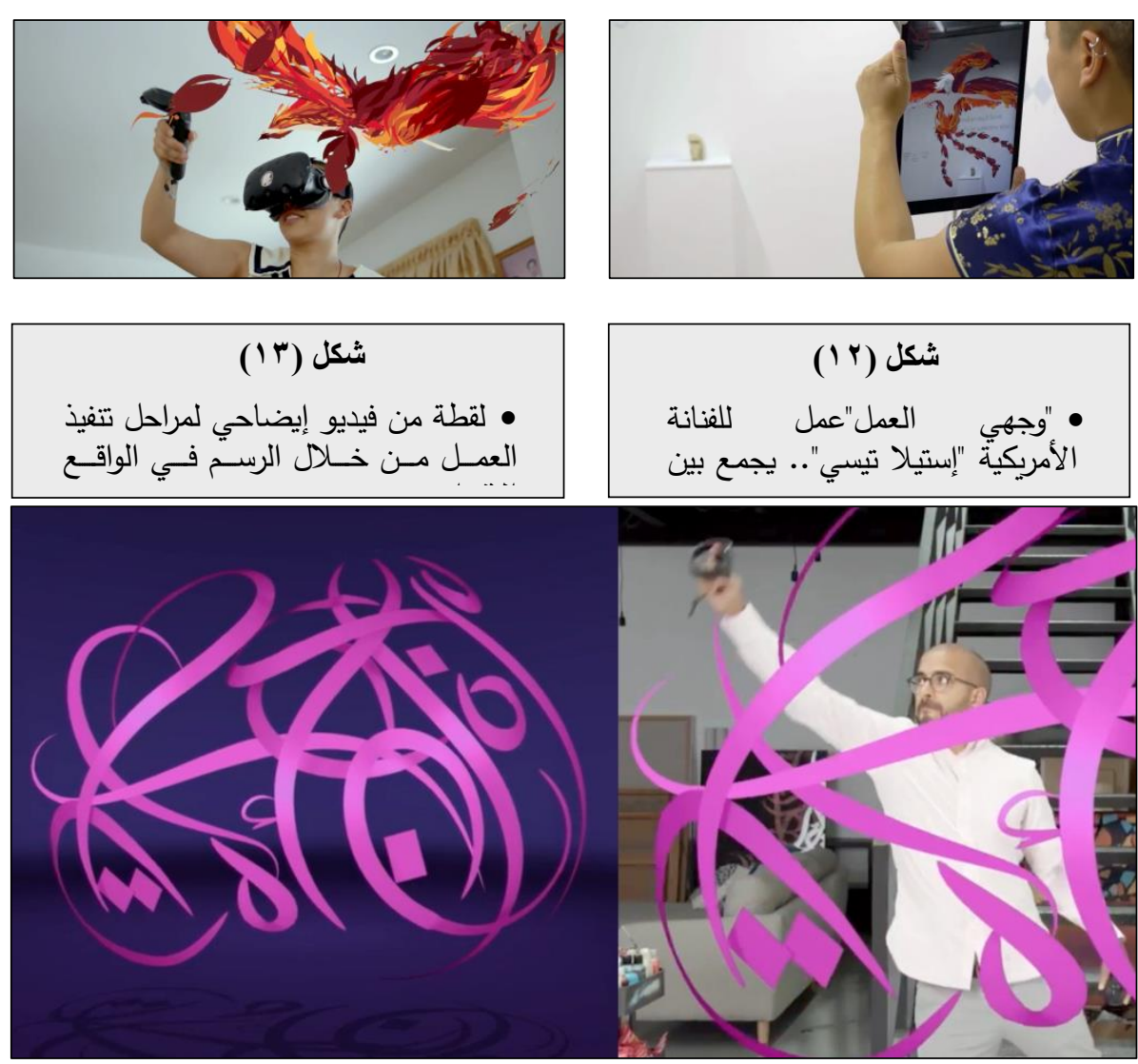

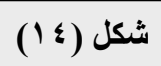

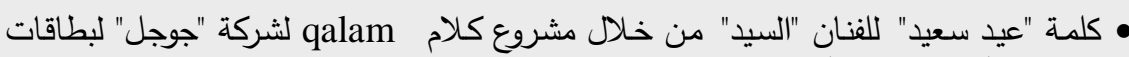

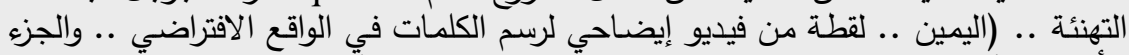

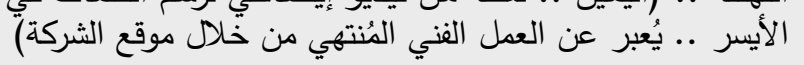

لمشاهدة طائر العنقاء

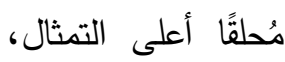
وهو يُمسك بين

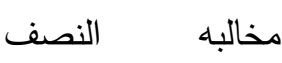
الآخر من وجها التمثال وقيد اكتملت هيئته الإنسانية ليمتد ذراعيه هو الآخر كأنه يُحلق .. ولتنفيذ

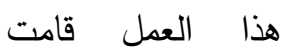
الفنانة بالرسم في الواقع الافتراضي في مراحل التنفيذ الأولى الأى من رسم طائر العنقاء والجسد الإنساني من رن خلال

Google's برنامج ش Tilt Brush (rآ) - ثم مُعالجة ذلك الرسم من خلال برمجيات شركة "أدوبي" لئصبح متاحًا

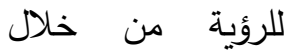
"الواقع المُعزز" .

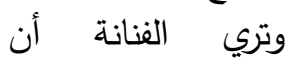

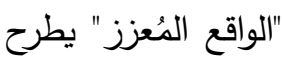
2)." صيغة للتفاعل مع العالم الحقيقي بصورة أفضل بخلاف الواقع الافتراضي الذي يُمثل انفصالاً تامًا

(1) https://futurism.com/videos/this-artist-uses-virtual-reality-as-a-medium

$$
\text { (بتصرف) بتاريخ } \wedge \text { مارس } 9 \text { 1 إبرم. }
$$

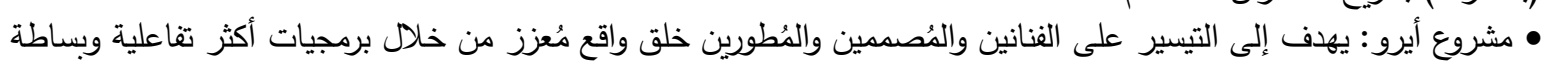

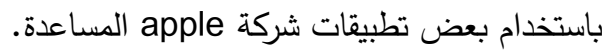

(2) https://vrscout.com/news/ar-exhibit-two-sides-of-reality/\#

$$
\text { (بتصرف) بتاريخ V مارس } 9 \text { 1 • rم. }
$$


• تطييق عملي للتصميم الخطي المرسوم من خلال الواقع الافتراضي

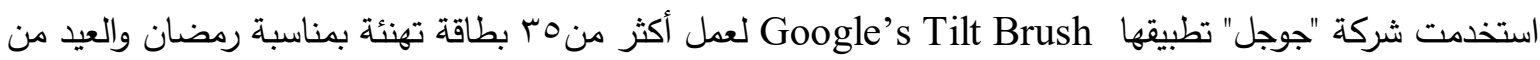

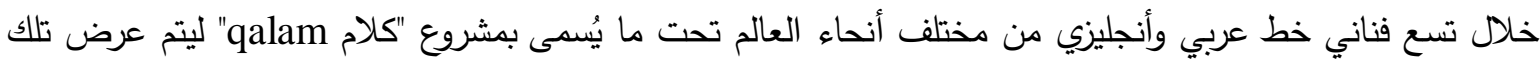

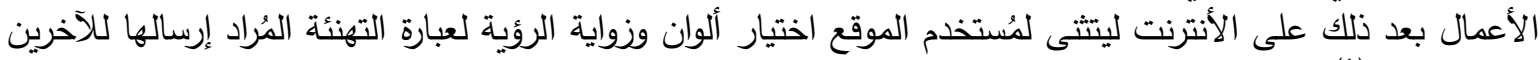

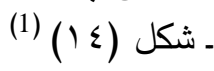

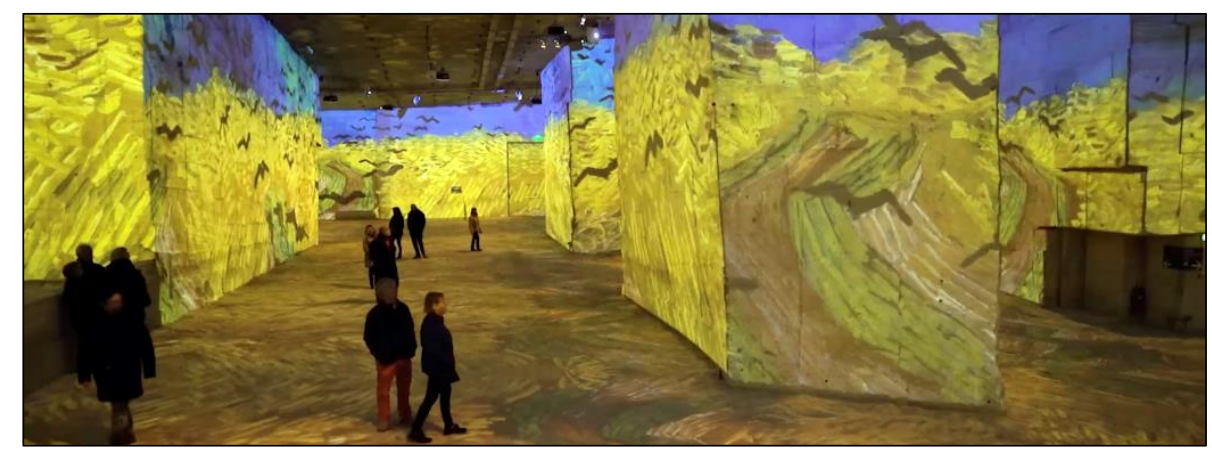

\section{شكل (10)}

• بـ الزوار يشاهدون أعمال الفنان الهولندي "فان جوخ" من خلال العرض الضوئي البانورامي

• • الايهام بالو اقع الافتر اضي من خلال العرض الضوئي الحائطي "فرنسا" (2)

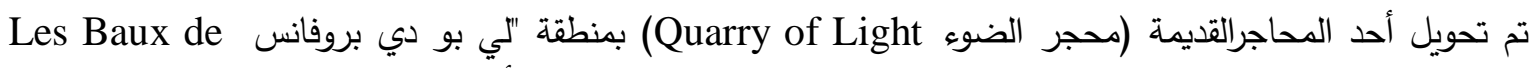

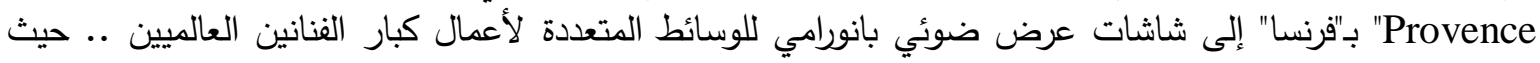

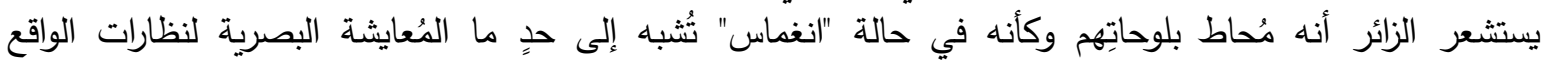
الافتراضي ـ شكل (10).

• تعليق

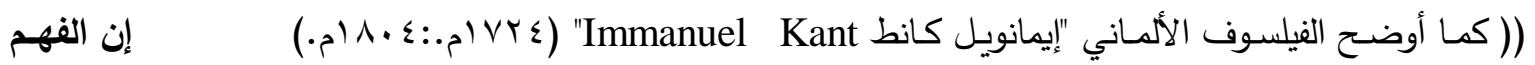

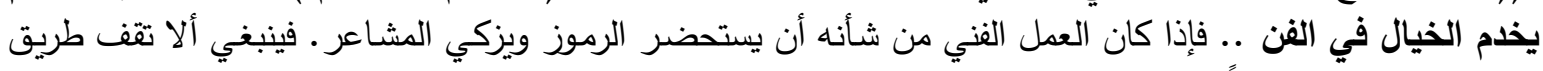

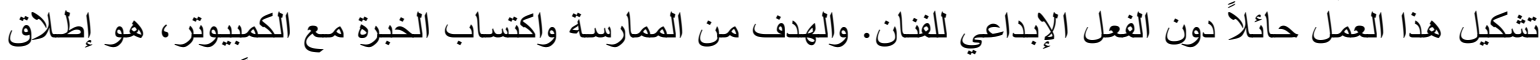

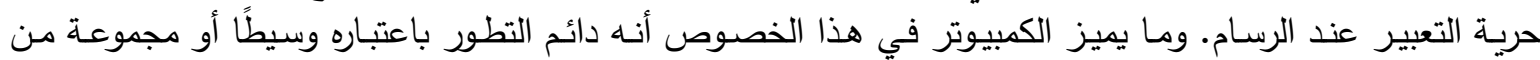

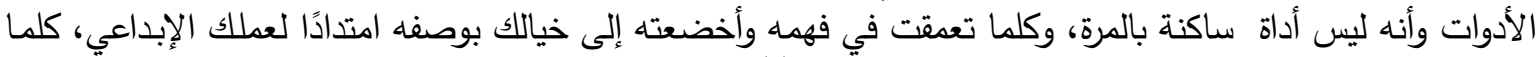

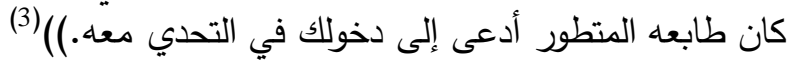

(1) https://www.blog.google/products/search/ramadan-kareem-get-ramadan-spirit-

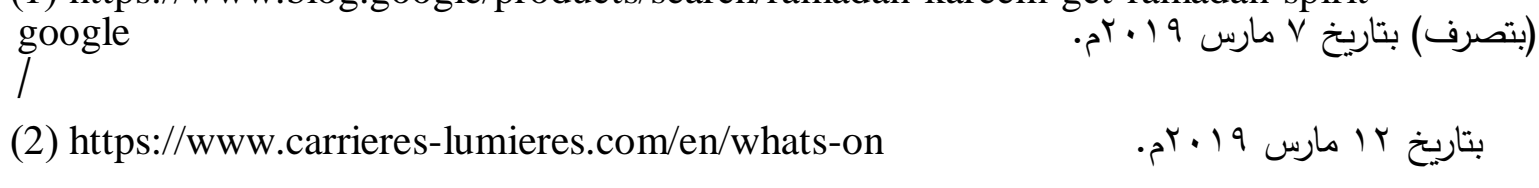
(3) مصطفى محمود ـ عينُ الفنان وعينُ الكمبيوتر ـ الهيئة العامة لقصور الثقافة ـ سلسلة الثقافة العلمية (ع ب) ـ الطبعة

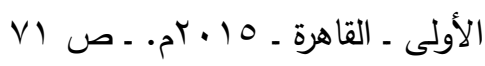


النتائج

• تلاشت الحدود الفاصلة بين مجالات الإبداع التشكيلي: الرسم والتصوير والنحت والتجهيز في الفراغ وفنون الإضاءة

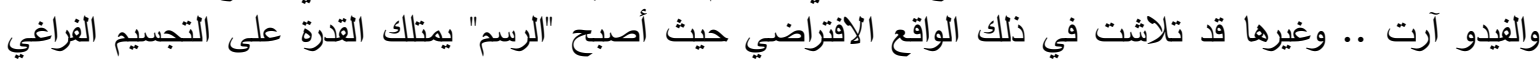

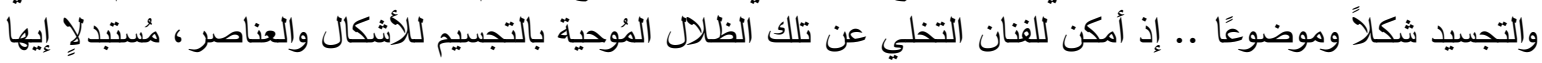
بتلك بالرسم مباشرة في عمق الفراغ الافتراضي.

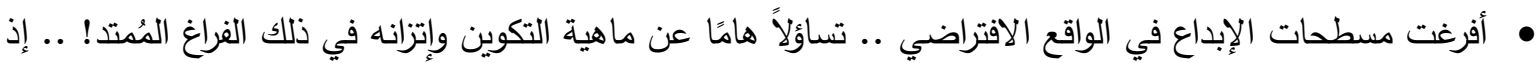
أصبح الفنان مُطالبًا بقراءة العمل الفني من أكثر من زاوية واتجاه، ما حدا بهابه إلى معالجة هيكله المرسوم وبناءِهِ بإسلوبٍ أقرب مايكون إلى النحت الميداني.

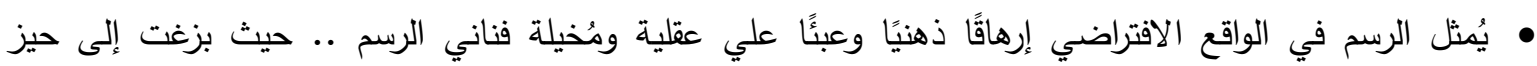

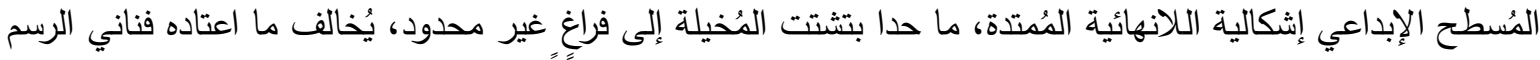

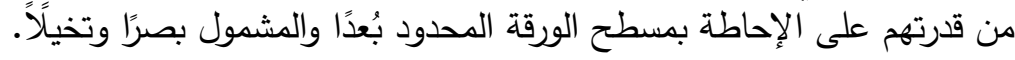

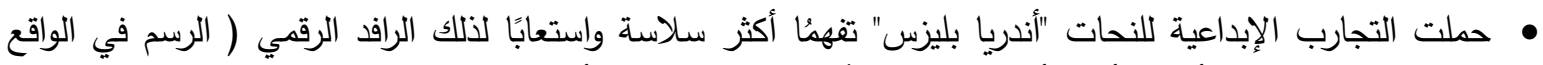

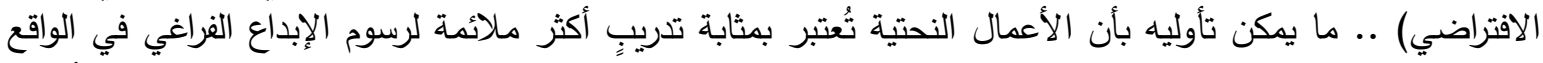

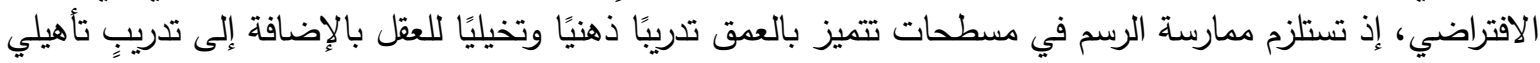

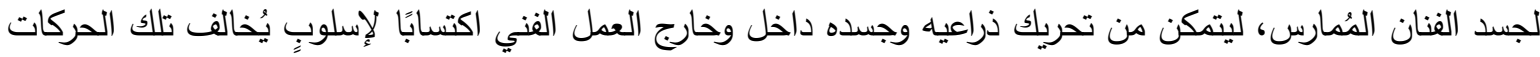

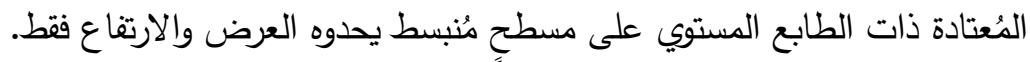
• العمل الفني المرسوم في الواقع الافتراضي أصبحت ممارسته أقرب ما تكون إلى الأداء الحركي المُّلازم لفناني

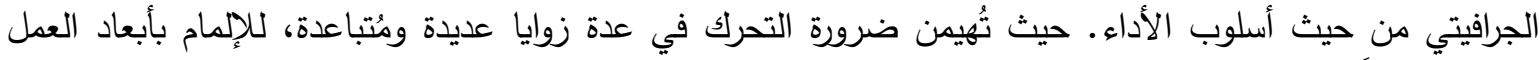

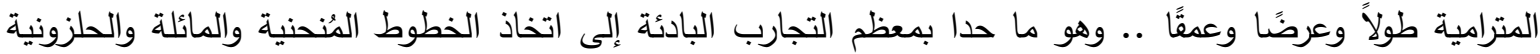
بالإضافة للكتابات إلى السيطرة على أغلب الإبداعات التجريبية، نظرًا لسلاسة الحركة الجسدية وقلة الإلى الإرهاق المُلازمتين لألك الأسلوب الفني.

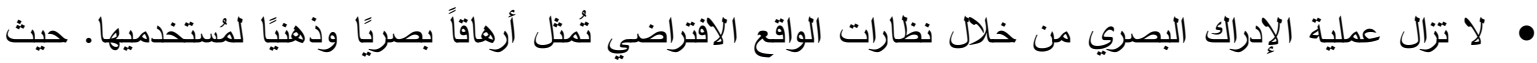

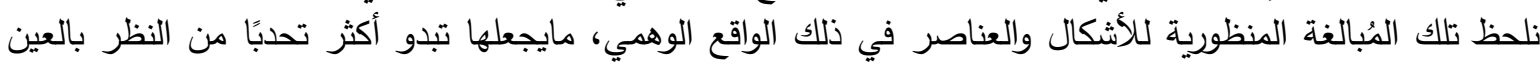

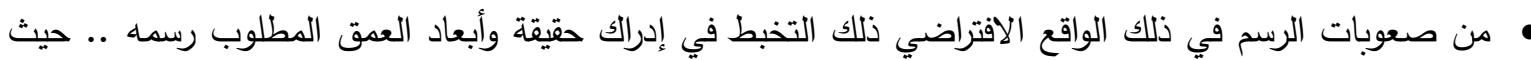

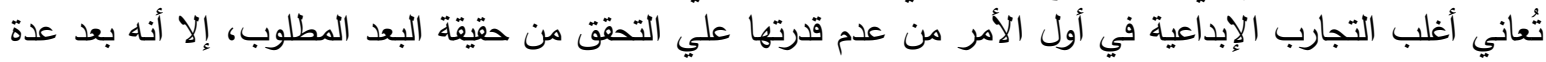

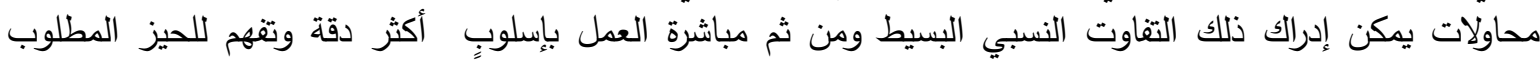

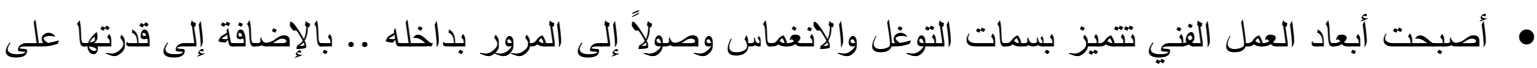

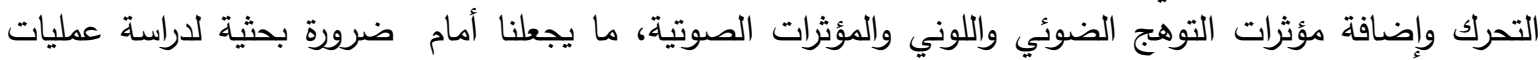

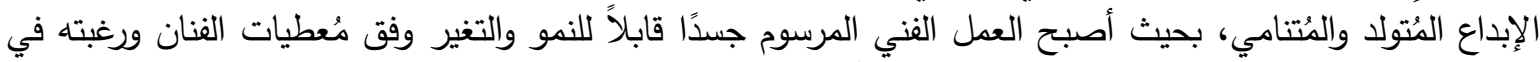

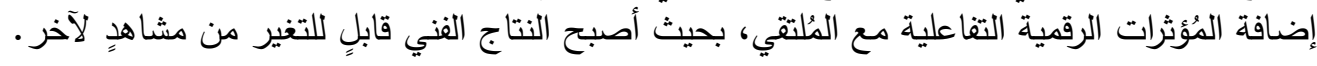

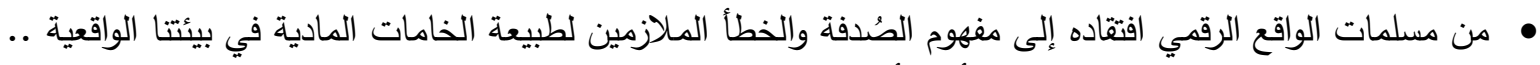

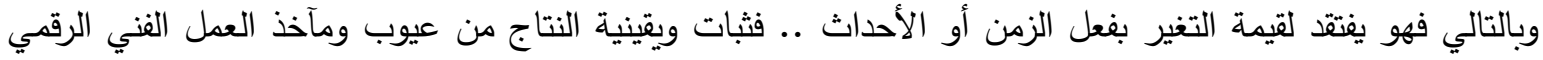

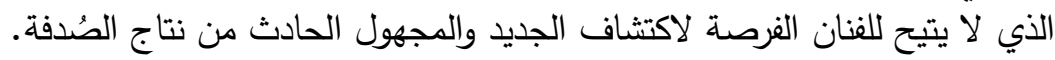
• لا تزال تكنولوجيات الواقع الافتراضي قيد التطوير من حيث التجهيزات والبرمجيات .. ماقد يجعلها محط أنظار عدادٍ

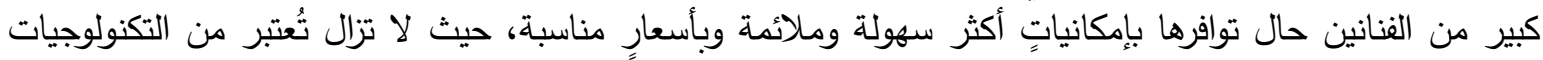
المُتقدمة في مجال الإبداع الرقمي.

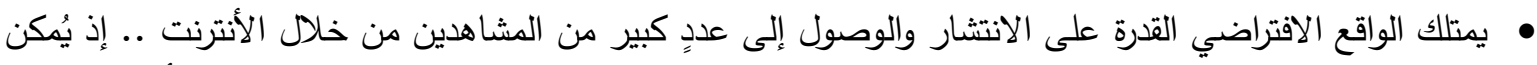

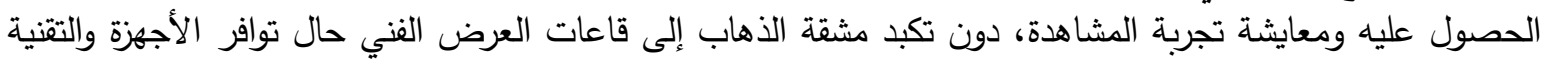




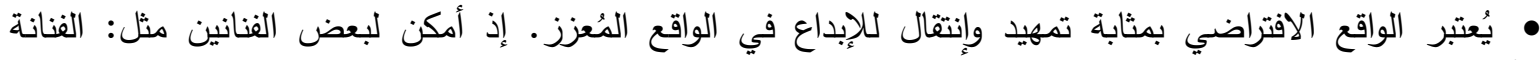

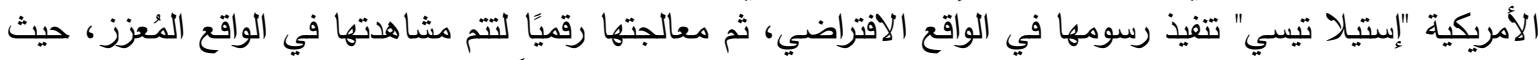

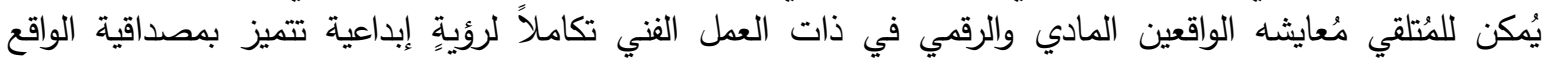
وابتكارية التقنية.

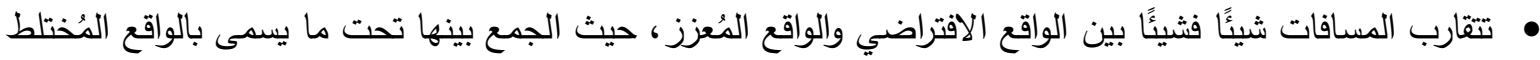

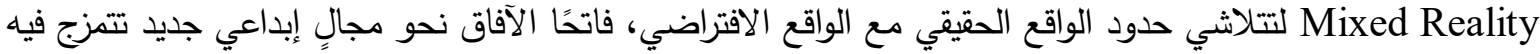

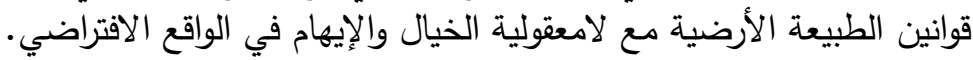

• إفساح المجال البحثي لمزيد من الدراسة حول آليات الإبداع في الواقع الافتراضي .. وذلك توثيقًا ونقلاً لتلك التجارب

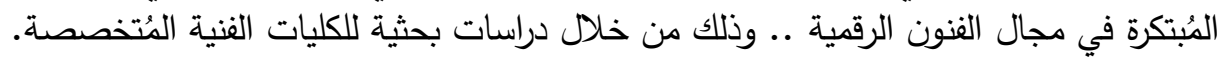

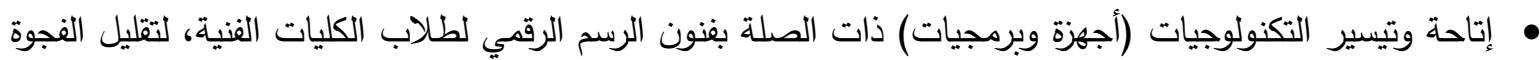

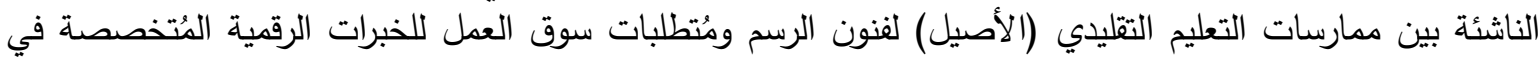
مجالات: الرسوم المتحركة والرسوم التوضيحية والتصميم الجرافيكي والإعلان والقصص الثُصنيات التصورة والكاريكاتير والوسائط المُتعددة. • التأكيد على أهمية متابعة التطورات المُتلاحقة في مجال البرمجيات ذات الصلة بفنون الرسم، لاكتشاف الجديد من الإمكانيات والإصدارات البرمجية المُيسرة لإبداع فني أَكثر تميزًا.

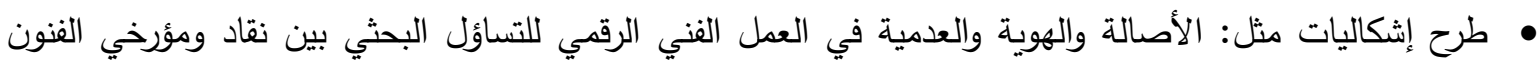

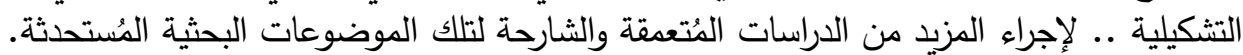

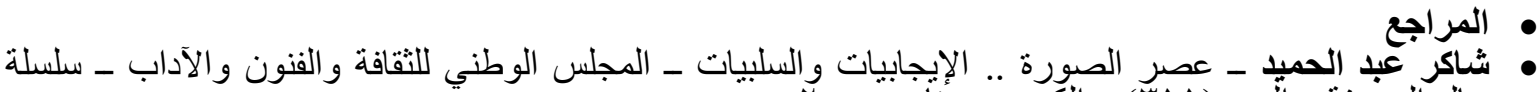

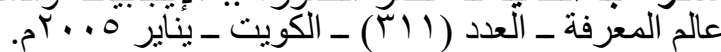

• ماهر عبد المحسن - جماليات الصورة في السيميوطيقا والفينومينولوجيا ـ الهيئة العامة لقصور الثقافة ـ سلسلة

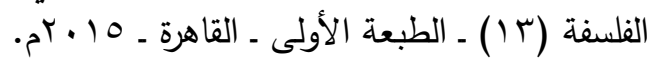

• مختار العطار ـ الفنون الجميلة بين المتعة والمنفعة ـ الهيئة المصرية العامة للكتاب بالتعاون مع الجمعية المصرية

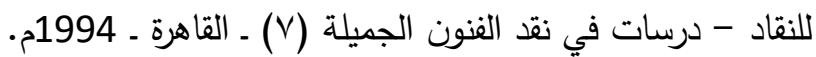

• مصطفى محمود ـ عينُ الفنان وعينُ الكمبيوتر ـ الهيئة العامة لقصور التقافة ـ سلسلة الثقافة العلمية (ع ؟) ـ الطبعة

- https://www.alukah.net/literature_language/0/5427/

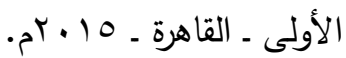

- http://www.baheth.info/all.jsp?term=وقع

- http://www.ergo-eg.com/ppt/2vra.pdf

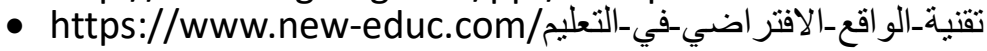

- http://www.ergo-eg.com/ppt/2vrb.pdf

- https://virtualart.chromeexperiments.com/\#/tech

- https://www.tiltbrush.com/air/

- https://theblog.adobe.com/project-dali-building-an-endless-creative-canvas-withvirtual-reality/

- https://futurism.com/videos/this-artist-uses-virtual-reality-as-a-medium

- https://vrscout.com/news/ar-exhibit-two-sides-of-reality

- https://www.blog.google/products/search/ramadan-kareem-get-ramadan-spiritgoogle/

- https://www.carrieres-lumieres.com/en/whats-on 